\title{
Magnetohydrodynamic Time-Dependent Bio-Nanofluid Flow in a Porous Medium with Variable Thermophysical Properties
}

\author{
M. Irfan $\mathbb{D}^{\mathbb{D}},{ }^{1}$ M. Asif Farooq $\mathbb{D}^{1},{ }^{1}$ A. Aslam, ${ }^{1}$ A. Mushtaq $\mathbb{D}^{2},{ }^{2}$ and Z. H. Shamsi $\mathbb{D}^{3}$ \\ ${ }^{1}$ Department of Mathematics, School of Natural Sciences (SNS), National University of Sciences and Technology (NUST), \\ Sector H-12, 44000, Islamabad, Pakistan \\ ${ }^{2}$ Seksjon for Matematikk, Nord Universitet, 8026 Bodø, Norway \\ ${ }^{3}$ Department of Mathematics, University of the Punjab, 54590 Lahore, Pakistan
}

Correspondence should be addressed to A. Mushtaq; asif.mushtaq@nord.no

Received 29 October 2020; Revised 12 March 2021; Accepted 29 March 2021; Published 14 April 2021

Academic Editor: Hafiz Muhammad Ali

Copyright ( ) 2021 M. Irfan et al. This is an open access article distributed under the Creative Commons Attribution License, which permits unrestricted use, distribution, and reproduction in any medium, provided the original work is properly cited.

\begin{abstract}
In this work, a theoretical model with a numerical solution is brought forward for a bio-nanofluid with varying fluid features over a slippery sheet. The partial differential equations (PDEs) involving temperature-dependent quantities have been translated into ordinary differential equations (ODEs) by using similarity variables. Numerical verifications have been done in three different methods: finite difference method, shooting method, and bvp4c. To figure out the influence of parameters on the flows, the graphs are plotted for the velocity, temperature, concentration, and microorganism curves. The boundary layer thickness of the microorganism profile reduces with the Schmidt number and Peclet number. In addition to adding radiative heat flux, we added heat generation, rate of chemical reaction, and first-order slip. Adding these parameters brought new aspects to the underlying profiles. Moreover, the obtained data of the skin friction coefficient, the local Nusselt number, the local Sherwood number, and the local density of motile microorganisms are tabulated against various parameters for the physical parameters. From the results, it is apparent that the local Nusselt number decreases with the Brownian and thermophoretic parameters. The data obtained for physical parameters have a close agreement with the published data. Finally, the graphs for slip conditions are significantly different when the comparison is drawn with no-slip condition.
\end{abstract}

\section{Introduction}

Thermal analysis has attracted attention from the scientific community because of its role in our daily lives. The applications of heat transfer range from electrical devices and power plants to the heating and cooling devices, boiler, condenser, and evaporators within houses where efficiency of these devices plays a key role. The efficient devices not only reduce energy consumption but also give additional life to it.

Nanofluid is a mixture of a base fluid with $100 \mathrm{~nm}$-size nanoparticles. Since the work by Choi and Eastman [1] on nanofluid, the research in this direction took a huge stride. The thermal conductivity is significantly higher than that of the traditional fluids as it was reported in Lee et al. [2]. There are many applications in the field of nanofluids including lubricants, automation, electronics, and biomedicine. For the list of references which took multiple paths considering nanofluid in their study, one is referred to in [3-7].

Bioconvection is another phenomenon which occurs due to the density difference of the fluid. Raees et al. [8] recorded the homotopy analysis method (HAM) solution for an unsteady bioconvection flow in a channel and showed that the velocity component decreases with the increase in time. Uddin et al. [9] discussed bioconvection nanofluid over a wavy surface with slip flow in application to nano-biofuel cells. Khan and Makinde [10] explored bioconvection flow due to gyrotactic microorganisms. They noticed that, with rising the values of the convective variable, the dimensionless temperature on the surface rises. Uddin et al. [11] investigated Stefan blowing with multiple slip effects in bioconvection. For finding similarity transformation, they used Lie group 
analysis. The resources for further study on this topic can be found in [12-16].

One of the ways through which heat transfer occurs is thermal radiation. It has diverse technological applications in combustion, furnace design, turbines, and solar collectors. The thermal radiation with variable fluid properties is reported in [17]. The author found that the skin friction coefficient increases with viscosity parameter. RamReddy and Naveen [18] reported results for activation energy and thermal radiation. Aziz et al. [19] discussed free convection flow in nanofluids with microorganisms. They discovered that the bioconvection parameter affects heat transfer rate. Mutuku and Makinde [20] discussed hydromagnetic fluid flow in microorganisms. Sk et al. [21] presented multiple slip effects in the presence of microorganisms. Anwar et al. [22] discussed MHD flow in a porous channel with generalized conditions. For further study on this topic, one is referred to in [23-25].

The magnetic field has many applications including geothermal energy extractions, plasma studies, chemical engineering, and magnetic resonance imaging (MRI) equipment [26]. Ali et al. [27] discussed hybrid nanofluid with slip conditions for Jeffrey fluid. Mburu et al. [28] reported magnetic and thermal radiation effects over an inclined cylinder. Mabood et al. [29] combined electrical and magnetic flows for non-Newtonian nanofluids over a thin needle.

The viscosity of the fluid generally depends on pressure and temperature. However, less effect in fluid flow is observed with pressure. Therefore, viscosity is dependent on the temperature variation. Fatunmbi and Adeniyan [30] reported nonlinear thermal radiation in fluid flow with variable properties. Dandapat et al. [31] discussed thin film unsteady flow with variable fluid properties. Vajravelu et al. [32] discussed unsteady convective flow in a vertical surface with variable fluid properties. Shahsavar et al. [33] investigated the impact of variable fluid properties in hybrid nanofluid. Naganthran et al. [34] found results of the stretching and shrinking sheet with variable fluid properties. They discussed dual solutions in this rotating disk. Salahuddin et al. [35] discussed variable fluid properties for viscoelastic fluid between two rotating plates.

Shafiq et al. [36] presented second-grade bioconvective nanofluid flow and computed the solution from the shooting method. In another study, Rasool and Shafiq [37] discussed Powell-Eyring nanofluid flow in a porous medium over a nonlinear surface. The porosity factor is enhancing the drag force. In another work by Shafiq et al. [38], the numerical solution of the bioconvective tangent hyperbolic nanofluid was found. The effect of temperature-dependent viscosity, thermal radiation, and gyrotactic phenomenon in a convection flow over a cylinder has been discussed in [39-41], respectively. In another work by Khan et al. [42], the bioconvection flow was discussed in a truncated cone. For critical review about nanofluid and its effects on viscosity along with thermal conductivity, the reader is referred to in [43-46]. For experimental investigation on nanofluids, the reader is referred to in [47].

Most theoretical studies mentioned above are focused on the idea of constant fluid properties in fluid flows. The viscosity of a fluid, however, relies heavily on temperature than on other factors, such as pressure. It comes out that the use of variable properties offers distinct effects on fluid flow motion.

This paper is ordered in the following way: the flow model is presented in Section 2. The numerical procedure for the solution is presented in Section 3. Results and discussion are given in Section 4. Conclusion of the paper is drawn in Section 5.

\section{Flow Model}

Consider the movement of a nanofluid containing gyrotactic microorganisms past a stretching sheet with variable physical properties. The magnetic field $\beta_{o}^{2}$ is applied normal to the surface. Due to low magnetic Reynolds number, the induced magnetic field is assumed negligible. The stretching velocity is $U_{w}=\operatorname{ax}\left(1-A_{1} t\right)^{-1}$. The governing model is [48]

$$
\begin{aligned}
& \frac{\partial \widehat{u_{1}}}{\partial x}+\frac{\partial \widehat{v_{1}}}{\partial y}=0 \\
& \frac{\partial \widehat{u_{1}}}{\partial t}+\widehat{u_{1}} \frac{\partial \widehat{u}_{1}}{\partial x}+\widehat{v_{1}} \frac{\partial \widehat{u_{1}}}{\partial y}=\frac{1}{\rho_{\infty}} \frac{\partial}{\partial y}\left(\mu\left(\widehat{T}_{1}\right) \frac{\partial \widehat{u}_{1}}{\partial y}\right)-\frac{\sigma \beta_{0}^{2}}{\rho_{\infty}} \widehat{u_{1}}-\frac{\mu(\widehat{T})}{\rho_{\infty} k^{*}} \widehat{u_{1}}, \\
& \frac{\partial \widehat{T}_{1}}{\partial t}+\widehat{u}_{1} \frac{\partial \widehat{T}_{1}}{\partial x}+\widehat{v}_{1} \frac{\partial \widehat{T}_{1}}{\partial y}=\frac{1}{\rho_{\infty} c_{p}} \frac{\partial}{\partial y}\left(k\left(\widehat{T}_{1}\right) \frac{\partial \widehat{T}_{1}}{\partial y}\right)+\tau_{1}\left(D_{B}(c) \frac{\partial \widehat{T}_{1}}{\partial y} \frac{\partial \widehat{C}_{1}}{\partial y}+\frac{D_{\widehat{T}_{1}}}{T_{\infty}}\left(\frac{\partial \widehat{T}_{1}}{\partial y}\right)^{2}\right) \\
& -\frac{1}{\rho_{\infty} c_{p}} \frac{\partial q_{r}}{\partial y}+\frac{\mu\left(\widehat{T}_{1}\right)}{\rho_{\infty} c_{p}}\left(\frac{\partial \widehat{u}_{1}}{\partial y}\right)^{2}+\frac{\left(\widehat{T}_{1}-T_{\infty}\right) Q}{\rho_{\infty} c_{p}}+\frac{\sigma B_{0}^{2} \widehat{u}_{1}^{2}}{\rho_{\infty} c_{p}}+\frac{\mu\left(\widehat{T}_{1}\right) \widehat{u}_{1}^{2}}{c_{p} k^{*}}, \\
& \frac{\partial \widehat{C}_{1}}{\partial t}+\widehat{u}_{1} \frac{\partial \widehat{C}_{1}}{\partial x}+\widehat{v}_{1} \frac{\partial \widehat{C}_{1}}{\partial y}=\frac{\partial}{\partial y}\left(D_{B}\left(\widehat{C}_{1}\right) \frac{\partial \widehat{C}_{1}}{\partial y}\right)+\frac{D_{\widehat{T}_{1}}}{T_{\infty}} \frac{\partial^{2} \widehat{T}_{1}}{\partial y^{2}}-\left(\widehat{C}_{1}-C_{\infty}\right) K_{c}, \\
& \frac{\partial \widehat{N}_{1}}{\partial t}+\widehat{u}_{1} \frac{\partial \widehat{N}_{1}}{\partial x}+{\widehat{v_{1}}}_{1} \frac{\partial \widehat{N}_{1}}{\partial y}+\frac{b w_{c}}{C_{w}-C_{\infty}}\left(\frac{\partial}{\partial y}\left(\widehat{N}_{1} \frac{\partial \widehat{C}_{1}}{\partial y}\right)\right)=\frac{\partial}{\partial y}\left(D_{m}\left(\widehat{C}_{1}\right) \frac{\partial \widehat{N}_{1}}{\partial y}\right),
\end{aligned}
$$


and the boundary condition corresponding to the considered model is taken as

$$
\begin{aligned}
& \widehat{u_{1}}=U_{w}(x, t)+N_{1} \frac{\partial \widehat{u}_{1}}{\partial y}, \quad v=0, \\
& \widehat{T}_{1}=T_{w}(x, t)+D_{1} \frac{\partial \widehat{T}_{1}}{\partial y}, \\
& \widehat{C}_{1}=C_{w}, \widehat{N}_{1}=N_{w}, \quad \text { at } y=0, \\
& \widehat{u_{1}} \longrightarrow 0, \widehat{T}_{1} \longrightarrow T_{\infty}, \\
& \widehat{C} \longrightarrow C_{\infty}, \widehat{N}_{1} \longrightarrow N_{\infty}, \quad \text { as } y \longrightarrow \infty
\end{aligned}
$$

where all the variables are defined in the glossary.

The similarity variables are defined as

$$
\begin{aligned}
\eta & =\sqrt{\frac{a}{v\left(1-A_{1} t\right)} y,} \\
\psi & =\sqrt{\frac{a v}{1-A_{1} t} x f(\eta),} \\
\theta(\eta) & =\frac{\widehat{T}_{1}-T_{\infty}}{T_{w}-T_{\infty}}, \\
\phi(\eta) & =\frac{\widehat{C}_{1}-C_{\infty}}{C_{w}-C_{\infty}}, \\
\chi(\eta) & =\frac{\widehat{N}_{1}}{N_{w}} .
\end{aligned}
$$

Inserting equation (7) into equations (1)-(6), we get

$$
\begin{aligned}
& \left(\frac{\mu\left(\widehat{T}_{1}\right)}{\mu_{\infty}} f^{\prime \prime}\right)^{\prime}-f^{\prime 2}+f f^{\prime \prime}-A\left(f^{\prime}+\frac{\eta}{2} f^{\prime \prime}\right)-\left(M+K p\left(\frac{\mu(\widehat{T})}{\mu_{\infty}}\right)\right) f^{\prime}=0 \\
& \left(\frac{k\left(\widehat{T}_{1}\right)}{k_{\infty}} \theta^{\prime}\right)^{\prime}+\frac{4}{3} \operatorname{Rd} \theta^{\prime \prime}+\mathrm{Nb}\left(\frac{D_{B}(\widehat{C})}{D_{B, \infty}}\right) \theta^{\prime} \phi^{\prime}+\mathrm{Nt} \theta^{\prime 2} \\
& +\operatorname{Pr}_{\infty}\left(f \theta^{\prime}-\frac{\eta A}{2} \theta^{\prime}+\operatorname{Ec}\left(\frac{\mu\left(\widehat{T}_{1}\right)}{\mu_{\infty}}\right) f^{\prime \prime^{2}}+\operatorname{MEcf}^{\prime 2}+\operatorname{EcKp}\left(\frac{\mu(\widehat{T})}{\mu_{\infty}}\right) f^{\prime 2}+s \theta\right)=0, \\
& \left(\frac{D_{B}(\widehat{C})}{D_{B, \infty}} \phi^{\prime}\right)^{\prime}+\frac{\mathrm{Nt}}{\mathrm{Nb}} \theta^{\prime \prime}+\mathrm{Sc}\left(f \phi^{\prime}-\frac{A \eta}{2} \phi^{\prime}-\mathrm{Kr} \phi\right)=0, \\
& \left(\frac{D_{m}(\widehat{C})}{D_{m, \infty}} \chi^{\prime}\right)^{\prime}+\operatorname{Sb}\left(f \chi^{\prime}-\frac{A \eta}{2} \chi^{\prime}\right)-\operatorname{Pe}\left(\phi^{\prime} \chi^{\prime}+\chi \phi^{\prime \prime}\right)=0 \\
& f(0)=0 \text {, } \\
& f^{\prime}(0)=1+\delta f^{\prime \prime}(0) \text {, } \\
& \theta(0)=1+\gamma \theta^{\prime}(0), \\
& \phi(0)=1 \text {, } \\
& \chi(0)=1 \text {, } \\
& f^{\prime}(\infty)=0 \text {, } \\
& \theta(\infty)=0 \text {, } \\
& \phi(\infty)=0 \text {, } \\
& \chi(\infty)=0 \text {. }
\end{aligned}
$$

Following Amirsom et al. [48], the physical quantities consisting of viscosity, thermal conductivity, nanoparticle, and microorganism diffusivities are written as

$$
\begin{aligned}
\mu\left(\widehat{T}_{1}\right) & =\mu_{\infty}\left[1+h_{1}\left(T_{\infty}-\widehat{T}_{1}\right)\right]=\mu_{\infty}\left(1+h_{2}-\theta h_{2}\right), \\
k\left(\widehat{T}_{1}\right) & =k_{\infty}\left[1+h_{3}\left(T_{\infty}-\widehat{T}_{1}\right)\right]=k_{\infty}\left(1+h_{4} \theta\right), \\
D_{B}\left(\widehat{C}_{1}\right) & =D_{B, \infty}\left[1+h_{5}\left(\widehat{C}_{1}-C_{\infty}\right)\right]=D_{B, \infty}\left(1+h_{6} \phi\right), \\
D_{m}\left(\widehat{C}_{1}\right) & =D_{m, \infty}\left[1+h_{7}\left(\widehat{C}_{1}-C_{\infty}\right)\right]=D_{m, \infty}\left(1+h_{8} \phi\right) .
\end{aligned}
$$


Equation (13) when used into equations (8)-(11), one can get

$$
\begin{aligned}
& \left(1+h_{2}-h_{2} \theta\right) f^{\prime \prime \prime}-h_{2} \theta^{\prime} f^{\prime \prime}-f^{\prime 2}+f f^{\prime \prime}-A\left(f^{\prime}+\frac{\eta}{2} f^{\prime \prime}\right)-\left(M+\operatorname{Kp}\left(1+h_{2}-h_{2} \theta\right)\right) f^{\prime}=0, \\
& \left(1+h_{4} \theta+\frac{4}{3} R d\right) \theta^{\prime \prime}+h_{4} \theta^{2}+\mathrm{Nb}\left(1+h_{6} \phi\right) \theta^{\prime} \phi^{\prime}+N_{t} \theta^{\prime 2} \\
& +\operatorname{Pr}_{\infty}\left(f \theta^{\prime}-\frac{A \eta}{2} \theta^{\prime}+\operatorname{Ec}\left(1+h_{2}-\theta h_{2}\right) f^{\prime \prime 2}+\operatorname{MEcf}^{\prime 2}+\operatorname{KpEc}\left(1+h_{2}-h_{2} \theta\right) f^{\prime 2}+s \theta\right)=0, \\
& \left(1+h_{6} \phi\right) \phi^{\prime \prime}+h_{6} \phi^{\prime 2}+\operatorname{Sc}\left(f \phi^{\prime}-\frac{A \eta}{2} \phi^{\prime}-\operatorname{Kr} \phi\right)+\frac{\mathrm{Nt}}{\mathrm{Nb}} \theta^{\prime \prime}=0, \\
& \left(1+h_{8} \phi\right) \chi^{\prime \prime}+h_{8} \phi^{\prime} \chi^{\prime}+\operatorname{Sb}\left(f \chi^{\prime}-\frac{A \eta}{2} \chi^{\prime}\right)-\operatorname{Pe}\left(\phi^{\prime} \chi^{\prime}+\chi \phi^{\prime \prime}\right)=0 .
\end{aligned}
$$

All these parameters are grouped into

$$
\begin{aligned}
& A=\frac{A_{1}}{a}, \\
& \mathrm{Kp}=\frac{\nu_{\infty}\left(1-A_{1} t\right)}{a k^{*}}, \\
& M=\frac{\sigma B_{o}^{2}\left(1-A_{1} t\right)}{\rho_{\infty} a}, \\
& \operatorname{Pr}_{\infty}=\frac{\nu_{\infty}}{\alpha_{\infty}}, \\
& \mathrm{Rd}=\frac{4 \sigma T_{\infty}^{3}}{k_{1} k_{\infty}}, \\
& \mathrm{Nb}=\frac{\tau_{1} D_{B, \infty}\left(C_{w}-C_{\infty}\right)}{\alpha_{\infty}}, \\
& \mathrm{Nt}=\frac{\tau_{1} D_{T}\left(T_{w}-T_{\infty}\right)}{T_{\infty} \alpha}, \\
& \mathrm{Ec}=\frac{u_{w}^{2}}{c_{p}\left(T_{w}-T_{\infty}\right)}, \\
& s=\frac{Q\left(1-A_{1} t\right)}{a}, \\
& \mathrm{Sc}=\frac{v_{\infty}}{D_{B, \infty}}, \\
& K_{r}=K_{c}\left(1-A_{1} t\right) a \text {, } \\
& \mathrm{Sb}=\frac{v_{\infty}}{D_{m, \infty}}, \\
& \mathrm{Pe}=\frac{\mathrm{bw}_{c}}{D_{m, \infty}}, \\
& \delta=N_{1}\left(\frac{a}{\nu_{\infty}\left(1-A_{1} t\right)}\right)^{(1 / 2)}, \\
& \gamma=D_{1}\left(\frac{a}{v_{\infty}\left(1-A_{1} t\right)}\right)^{(1 / 2)} \text {. }
\end{aligned}
$$

The physical quantities of the interest in this study are the local skin friction coefficient $C_{f x}$, the local Nusselt number $\mathrm{Nu}_{x}$, the local Sherwood number $\mathrm{Sh}_{x}$, and the local density number of motile microorganisms $\mathrm{Nn}_{x}$ defined as

$$
\begin{aligned}
C_{f x} & =\frac{\mu(T)(\partial u / \partial y)_{y=0}}{\rho u_{w}^{2}}, \\
\mathrm{Nu}_{x} & =\frac{-k(T) x(\partial T / \partial y)_{y=0}}{k(T)\left(T_{w}-T_{\infty}\right)}, \\
\mathrm{Sh}_{x} & =\frac{-D_{B, \infty} x(\partial C / \partial y)_{y=0}}{D_{B, \infty}\left(C_{w}-C_{\infty}\right)}, \\
\mathrm{Nn}_{x} & =\frac{-D_{m, \infty} x(\partial N / \partial y)_{y=0}}{\left(D_{m, \infty} N_{w}\right)} .
\end{aligned}
$$

Inserting equation (7) into equation (13) yields the following expressions:

$$
\begin{aligned}
\operatorname{Re}_{x}^{1 / 2} C_{f x} & =-\left(1+h_{2} \phi\right) f^{\prime \prime}(0), \\
\operatorname{Re}_{x}^{-1 / 2} \mathrm{Nu}_{x} & =-\left(1+\frac{4}{3} R d\right) \theta^{\prime}(0), \\
\operatorname{Re}_{x}^{-1 / 2} \mathrm{Sh}_{x} & =-\phi^{\prime}(0), \\
\operatorname{Re}_{x}^{-1 / 2} \mathrm{Nn}_{x} & =-\chi^{\prime}(0)
\end{aligned}
$$

where the local Reynolds number is defined as $\operatorname{Re}_{x}=\left(U_{w} x / \nu\right)$.

\section{Numerical Process}

3.1. Shooting Method. A boundary value problem ((8)-(12)) can be solved with the shooting method. The stable iterative scheme, Newton-Raphson method, has been used in locating the roots followed by obtaining the solution from the fifth-order Runge-Kutta solver. The system of first-order ODEs is 
Mathematical Problems in Engineering

5

$$
\begin{aligned}
f= & y_{1}, f^{\prime}=y_{2}, f^{\prime \prime}=y_{3}, \\
f^{\prime \prime \prime}= & y_{3}^{\prime}=\frac{1}{\left(1+h_{2}-y_{4} h_{2}\right)}\left(h_{2} y_{5} y_{3}+y_{2}^{2}-y_{1} y_{3}\right) A\left(y_{2}+\frac{\eta}{2} y_{3}\right)+\left(M+\operatorname{Kp}\left(1+h_{2}-h_{2} y_{4}\right) y_{2}\right), \\
y_{4}= & \theta, y_{5}=\theta^{\prime}, \theta^{\prime \prime}=y_{5}^{\prime}=\frac{-1}{\left(1+h_{4} y_{4}+(4 / 3) \mathrm{Rd}\right)} \\
& \cdot\left(h_{4} y_{5}^{2}+\mathrm{Nb}\left(1+h_{6} y_{6}\right) y_{5} y_{7}+\mathrm{Nt} y_{5}^{2}+\operatorname{Pr}_{\infty}\left(y_{1} y_{5}-\frac{\eta}{2} A y_{5}+\operatorname{Ec}\left(1+h_{2}-y_{2} y_{4}\right) y_{3}^{2}+s y_{4}+\operatorname{MEc} y_{2}^{2}+\operatorname{KpEc}\left(1+h_{2}-h_{2} y_{4}\right) y_{2}^{2}\right)\right. \\
y_{6}= & \phi, y_{7}=\phi^{\prime}, \phi^{\prime \prime}=y_{7}^{\prime} \\
= & \frac{-1}{\left(1+h_{6} y_{6}\right)}\left(\frac{N_{t}}{N_{b}} y_{5}^{\prime}+h_{6} y_{7}^{2}+\operatorname{Sc} y_{1} y_{7}+\frac{\operatorname{Sc} \eta A}{2} y_{7}-\operatorname{ScKr} y_{6}\right), \\
y_{8}= & \chi, y_{9}=\chi^{\prime}, \chi^{\prime \prime}=y_{9}^{\prime}=\frac{-1}{\left(1+h_{8} y_{6}\right)}\left(h_{8} y_{7} y_{9}-\operatorname{Sb}\left(\frac{\eta A}{2} y_{9}-y_{1} y_{9}\right)-\operatorname{Pe}\left(y_{7} y_{9}+y_{8} y_{7}^{\prime}\right)\right) .
\end{aligned}
$$

The results' verification is achieved from the bvp4c solver. For details on bvp4c, the reader is referred to in [49].
3.2. Finite Difference Method. In this section, we present the finite difference method to solve boundary value problem (8)-(12). The spatial discretization is given by first defining $f^{\prime}=F$ in the momentum equation:

$$
\begin{aligned}
(1 & \left.+h_{2}-h_{2} \theta_{i}\right)\left(\frac{F_{i+2}-2 F_{i+1}+F_{i}}{(\Delta \eta)^{2}}\right)-h_{2} \theta_{i}\left(\frac{F_{i+1}-F_{i}}{\Delta \eta}\right)-F_{i}^{2}+f_{i}\left(\frac{F_{i+1}-F_{i}}{\Delta \eta}\right) \\
& -A\left(F_{i}+\frac{\eta}{2}\left(\frac{F_{i+1}-F_{i}}{\Delta \eta}\right)\right)-\left(M-\mathrm{Kp}\left(1+h_{2}-h_{2} \theta_{i}\right)\right) F_{i}=0 \\
& \cdot\left(1+h_{4} \theta_{i}+\frac{4}{3} \mathrm{Rd}\right)\left(\frac{\theta_{i+2}-2 \theta_{i+1}+\theta_{i}}{(\Delta \eta)^{2}}\right)+\left(h_{4}+\mathrm{Nt}\right)\left(\frac{\theta_{i+1}-\theta_{i}}{\Delta \eta}\right)^{2} \\
& +\mathrm{Nb}\left(1+h_{6} \phi_{i}\right)\left(\frac{\theta_{i+1}-\theta_{i}}{\Delta \eta}\right)\left(\frac{\phi_{i+1}-\phi_{i}}{\Delta \eta}\right)+\mathrm{Pr}_{\infty}\left(f_{i}\left(\frac{\theta_{i+1}-\theta_{i}}{\Delta \eta}\right)-A \frac{\eta}{2}\left(\frac{\theta_{i+1}-\theta_{i}}{\Delta \eta}\right)+\mathrm{Ec}\left(1+h_{2}-h_{2} \theta_{i}\right)\right. \\
& +\left(\frac{F_{i+1}-F_{i}}{\Delta \eta}\right)^{2}+\mathrm{MEc} F_{i}^{2}+\mathrm{KpEc}\left(1+h_{2}-h_{2} \theta_{i}\right) F_{i}^{2}+s \theta_{i}=0 \\
& \left(1+h_{6} \phi_{i}\right)\left(\frac{\phi_{i+2}-2 \phi_{i+1}+\phi_{i}}{(\Delta \eta)^{2}}\right)+h_{6}\left(\frac{\phi_{i+1}-\phi_{i}}{\Delta \eta}\right)^{2} \\
& +\mathrm{Sc}\left(f_{i}\left(\frac{\phi_{i+1}-\phi_{i}}{\Delta \eta}\right)-A \frac{\eta}{2}\left(\frac{\phi_{i+1}-\phi_{i}}{\Delta \eta}\right)-\mathrm{Kr}_{i}+\frac{\mathrm{Nt}}{\mathrm{Nb}}\left(\frac{\theta_{i+2}-2 \theta_{i+1}+\theta_{i}}{(\Delta \eta)^{2}}\right)=0\right. \\
& +\left(1+h_{8} \phi_{i}\right)\left(\frac{\chi_{i+2}-2 \chi_{i+1}+\chi_{i}}{(\Delta \eta)^{2}}\right)+h_{8}\left(\frac{\phi_{i+1}-\phi_{i}}{\Delta \eta}\right)\left(\frac{\chi_{i+1}-\chi_{i}}{\Delta \eta}\right)+\mathrm{Sb}\left(f_{i}-A \frac{\eta}{2}\right)\left(\frac{\chi_{i+1}-\chi_{i}}{\Delta \eta}\right) \\
& \left.\operatorname{Pe}\left(\frac{\phi_{i+1}-\phi_{i}}{\Delta \eta}\right)\left(\frac{\chi_{i+1}-\chi_{i}}{\Delta \eta}\right)+\chi_{i}\left(\frac{\phi_{i+2}-2 \phi_{i+1}+\phi_{i}}{(\Delta \eta)^{2}}\right)\right)=0 \\
&
\end{aligned}
$$

and the boundary conditions are 


$$
\begin{aligned}
& f_{0}=0 \\
& F_{0}=1+\delta\left(\frac{F_{1}-F_{0}}{\Delta \eta}\right), \\
& \theta_{0}=1+\gamma\left(\frac{\theta_{1}-\theta_{0}}{\Delta \eta}\right) \\
& \phi_{0}=1, \chi_{0}=1, F_{\infty}=0, \theta_{\infty}=0, \phi_{\infty}=0, \chi_{\infty}=0 .
\end{aligned}
$$

\section{Results and Discussion}

An excellent agreement with published results is obtained for a comparison of the skin friction coefficient $-f^{\prime \prime}(0)$ which is shown in Tables 1-3.

The data in Table 4 show computational results for the local Nusselt number, the local Sherwood number, and the local density number of motile microorganisms obtained with bvp4c. The local Nusselt number $\mathrm{Nu}_{x}$ is reduced against Brownian motion parameter $\mathrm{Nb}$, thermophoretic parameter $\mathrm{Nt}$, Eckert number Ec, heat source parameter $s$, and thermal conductive parameter $h_{4}$.

With increasing values of Prandtl number $\operatorname{Pr}_{\infty}$ and radiation parameter $\mathrm{Rd}$, the local Nusselt number shows an upward trend.

The physical parameter, the local Sherwood number $\mathrm{Sh}_{x}$, depicts an upward trend against Brownian motion parameter $\mathrm{Nb}$, thermophoretic parameter $\mathrm{Nt}$, Schmidt number $\mathrm{Sc}$, and chemical reaction parameter Kr. However, a decreasing trend for the local Sherwood number is observed for rising values of mass diffusivity parameter $h_{6}$.

Finally, the values of the local density number of motile microorganisms $\mathrm{Nn}_{x}$ decline with the increase of mass diffusivity parameter $h_{6}$ and microorganism diffusivity parameter $h_{8}$. However, there is an upsurge for increasing values of the bioconvection Schmidt number Sb and Peclet number Pe.

Figures 1 and 2 illustrate the effects of magnetic parameter $M$ and porosity parameter Kp on the velocity profile with and without hydrodynamic slip. The boundary layer thickness reduces with increasing values of $M$ and Kp. When fluid flow encounters the Lorentz forces, the velocity of the fluid decelerates which affects the boundary layer thickness. The same argument holds for Kp.

Figure 3 is plotted to perceive the effect of Prandtl number $\operatorname{Pr}_{\infty}$ on the temperature profile. It is noted that an enhancement in Prandtl number $\operatorname{Pr}_{\infty}$ causes reduction in the temperature distribution. The smaller values of $\operatorname{Pr}_{\infty}$ correspond to the increase in thermal conductivities which causes reduction in a thermal boundary layer. For Prandtl number $(\operatorname{Pr} \geq 1)$, the momentum diffusivity is dominant in fluid behavior. Thus, less thermal diffusivity contributes to lowering the thermal boundary layer thickness.

Figure 4 depicts the influence of radiation parameter $\mathrm{Rd}$ on the temperature profile. It is seen that an increase in $\mathrm{Rd}$ enhances the temperature of the fluid. Larger values of radiation parameter transfer more heat to the fluid which overall increases the temperature and its profile.

Figure 5 reports the influence of Eckert number Ec on the temperature profile. The higher values of Eckert number Ec cause an increase in the thermal boundary layer thickness. The Eckert number Ec enhances kinetic energy, which increases fluid's temperature.

Figure 6 illustrates the impact of heat source parameter $s$ on the temperature distribution. It is observed that temperature of the fluid increases with an increment in the heat generation parameter. The higher values of $s$ provide more heat to the fluid resulting in the rise of the temperature of the fluid.

Figure 7 examines the effect of temperature-dependent thermal conductivity parameter $h_{4}$ on temperature. It is noted that the thermal boundary layer thickness increases by increasing parameter $h_{4}$.

Figures 8 and 9 are drawn to perceive the effect of Brownian motion parameter $\mathrm{Nb}$ on the temperature and concentration profiles. It is revealed in the figure that, by increasing Brownian motion parameter $\mathrm{Nb}$, thermal boundary layer thickness rises, while concentration boundary layer thickness declines. The Brownian parameter appears due to the presence of nanoparticles' concentration.

Figures 10 and 11 convey the impacts of thermophoresis parameter $\mathrm{Nt}$ on temperature and concentration distributions. The temperature and concentration profile rise for rising values of $\mathrm{Nt}$. The thermophoresis term appears due to the temperature gradient in particulate flows. Larger values of $\mathrm{Nt}$ transmit more temperature to the fluid along with the concentration profile.

Figure 12 portrays the influence of chemical reaction parameter $\mathrm{Kr}$ on the concentration profile. The rising values of $\mathrm{Kr}$ suppress diffusion which lowers the concentration boundary layer.

Figure 13 depicts the effects of Schmidt number Sc on the concentration distribution. The rise in Sc causes reduction in the concentration profile. The higher the Schmidt number, the lower the mass diffusivity which is the reason for reduction in the concentration boundary layer thickness.

Figure 14 presents the influence of mass diffusivity parameter $h_{6}$ on the concentration profile. One can observe that rise in mass diffusivity parameter $h_{6}$ results in an increase of the concentration profile.

Figure 15 describes the influence of Peclet number Pe on the density of motile microorganism profile. The incremental values of Peclet number Pe cause reduction in motile microorganisms' boundary layer thickness. The Peclet number appears in the study of transport processes. It measures the importance of convection over diffusion. For larger values of the Peclet number, the convection is dominant and diffusion is negligible which is happening here in the motile microorganisms' boundary layer thickness.

Figure 16 investigates the impact of bioconvection Schmidt number Sb on the density of motile microorganism profile. It is shown that rising values of bioconvection Schmidt number Sb lower the boundary layer thickness of 
TABLE 1: Comparison of skin friction coefficient $-f^{\prime \prime}(0)$ for different values of $M$ when $\operatorname{Pr}_{\infty}=1$ and $\mathrm{Kp}=\delta=\gamma=h_{2}=h_{4}=h_{6}=h_{8}=0$.

\begin{tabular}{|c|c|c|c|c|c|}
\hline$M$ & Hayat et al. [50] & Mabood and Mastroberardino [51] & Amirsom et al. [48] & Shooting method & bvp4c \\
\hline 0 & 1.0000 & 1.000008 & 1.0000002 & 1.0000 & 1.0001 \\
\hline 1 & 1.41421 & 1.4142135 & 1.41422211 & 1.4142 & 1.4142 \\
\hline 5 & 2.44948 & 2.4494897 & 2.4494901 & 2.4495 & 2.4495 \\
\hline 10 & 3.31662 & 3.3166247 & 3.3166229 & 3.3166 & 3.3166 \\
\hline 50 & 7.14142 & 7.1414284 & 7.1414279 & 7.1414 & 7.1414 \\
\hline 100 & 10.04987 & 10.049875 & 10.049868 & 10.0499 & 10.0499 \\
\hline 500 & 22.38302 & 22.383029 & 22.383031 & 22.3830 & 22.3830 \\
\hline 1000 & 31.63858 & 31.638584 & 31.638578 & 31.6386 & 31.6386 \\
\hline
\end{tabular}

TABLE 2: Comparison of skin friction coefficient $-f^{\prime \prime}(0)$ for different values of $M$ when $\operatorname{Pr}_{\infty}=1$ and $\mathrm{Kp}=\delta=\gamma=h_{2}=h_{4}=h_{6}=h_{8}=0$.

\begin{tabular}{|c|c|c|c|c|}
\hline$M$ & Hayat et al. [50] & Mabood and Mastroberardino [51] & Amirsom et al. [48] & FDM \\
\hline 0 & 1.0000 & 1.000008 & 1.0000002 & 1.0001 \\
\hline 1 & 1.41421 & 1.4142135 & 1.41422211 & 1.4142 \\
\hline 5 & 2.44948 & 2.4494897 & 2.4494901 & 2.4495 \\
\hline 10 & 3.31662 & 3.3166247 & 3.3166229 & 3.3166 \\
\hline 50 & 7.14142 & 7.1414284 & 7.1414279 & 7.1414 \\
\hline 100 & 10.04987 & 10.049875 & 10.049868 & 10.0499 \\
\hline 500 & 22.38302 & 22.383029 & 22.383031 & 22.3830 \\
\hline 1000 & 31.63858 & 31.638584 & 31.638578 & 31.6386 \\
\hline
\end{tabular}

TABle 3: Comparison of skin friction coefficient $-f^{\prime \prime}(0)$ for different values of $\delta$ when $\operatorname{Pr}_{\infty}=1$ and $\mathrm{Kp}=M=\gamma=h_{2}=h_{4}=h_{6}=h_{8}=0$.

\begin{tabular}{lcccr}
\hline$\delta$ & Andersson [52] & Hamad et al. [53] & Amirsom et al. [48] & Shooting method \\
\hline 0 & 1.0000 & 1.00000000 & 1.00000000 & 1.0000 \\
0.1 & 0.8721 & 0.87208247 & 0.87204247 & 0.8721 \\
0.2 & 0.7764 & 0.77637707 & 0.77593307 & 0.7764 \\
0.5 & 0.5912 & 0.59119548 & 0.59119589 & 0.5912 \\
1.0 & 0.4302 & 0.43015970 & 0.43016000 & 0.4302 \\
2.0 & 0.2840 & 0.28397959 & 0.28398932 & 0.2840 \\
5.0 & 0.1448 & 0.14484019 & 0.14464015 & 0.1448 \\
10.0 & 0.0812 & 0.08124198 & 0.08124091 & 0.0812 \\
20.0 & 0.0438 & 0.04378834 & 0.04378790 & 0.0438 \\
50.0 & 0.0186 & 0.01859623 & 0.01857868 & 0.4303 \\
100.0 & 0.0095 & 0.00954997 & 0.00954677 & 0.0186 \\
\hline
\end{tabular}

the motile microorganism profile. In high values of Sb, the particles are giant which means these diffuse slowly.

Figures 17 and 18 are drawn to perceive the effect of mass diffusivity parameter $h_{6}$ and microorganism diffusivity parameter $h_{8}$. Increasing the values of mass diffusivity parameter and microorganism diffusivity parameter elevates the boundary layer thickness of the motile microorganism profile. 


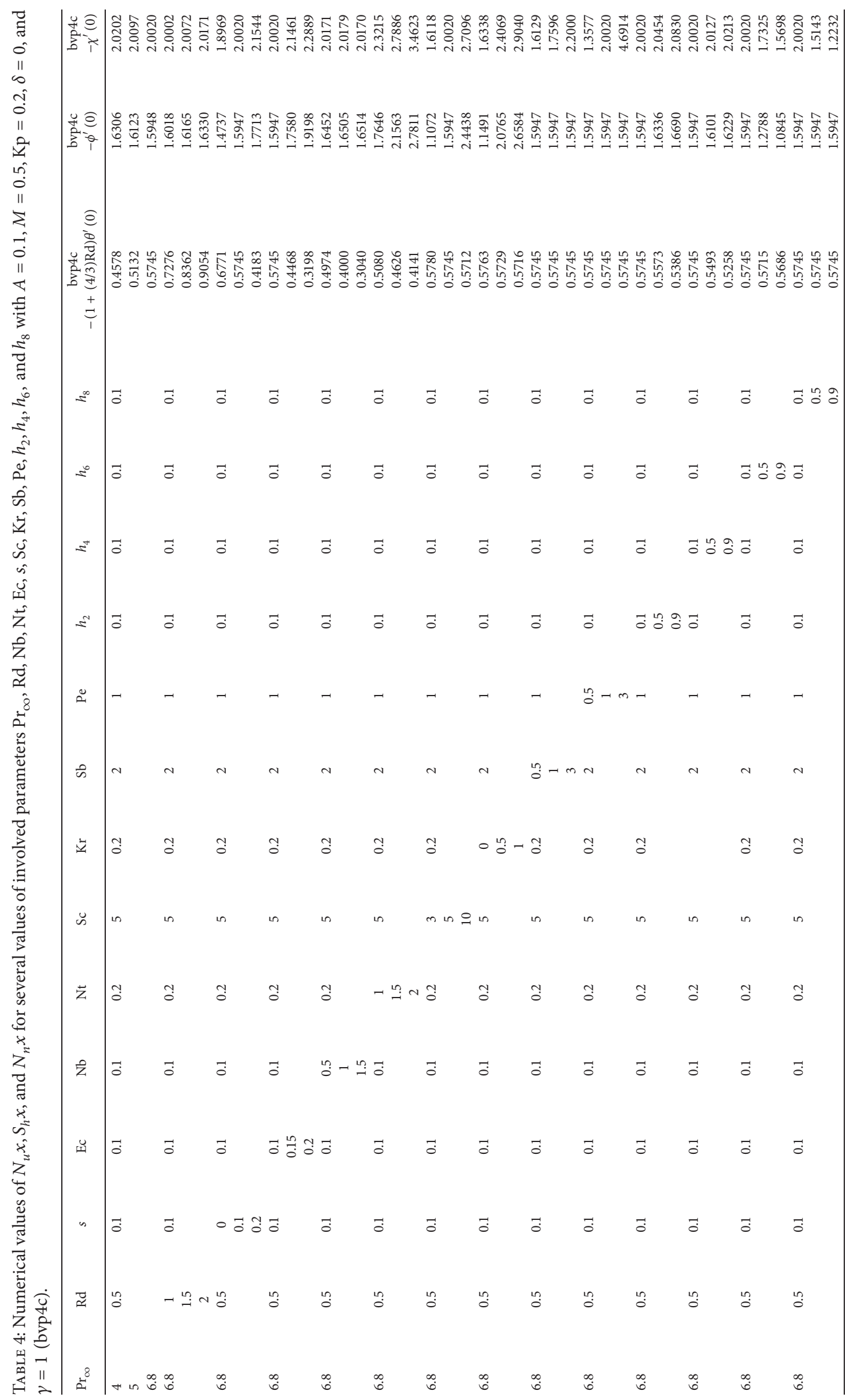




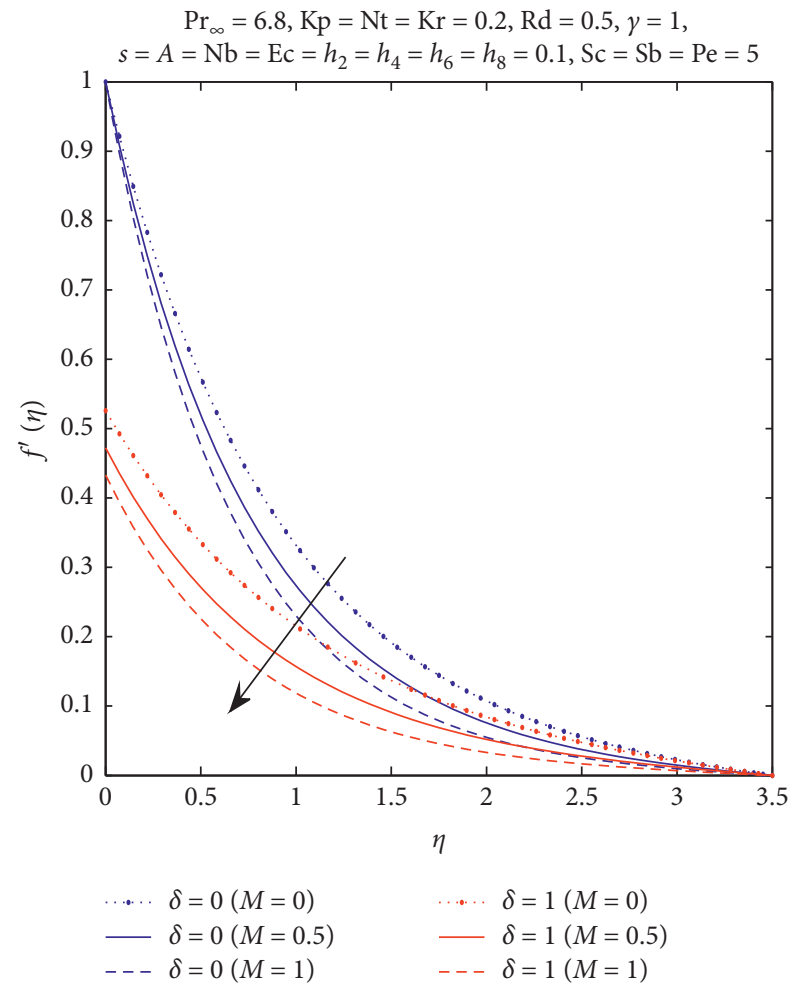

Figure 1: Velocity profile $f^{\prime}(\eta)$ for different $M$.

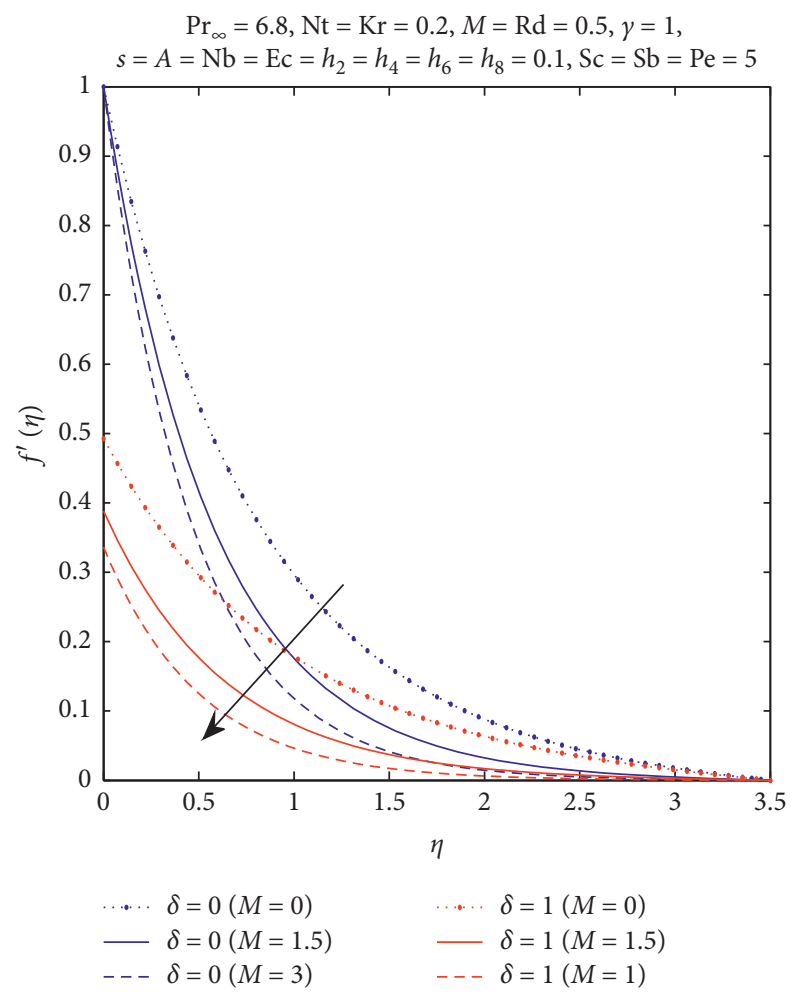

Figure 2: Velocity profile $f^{\prime}(\eta)$ for different Kp.

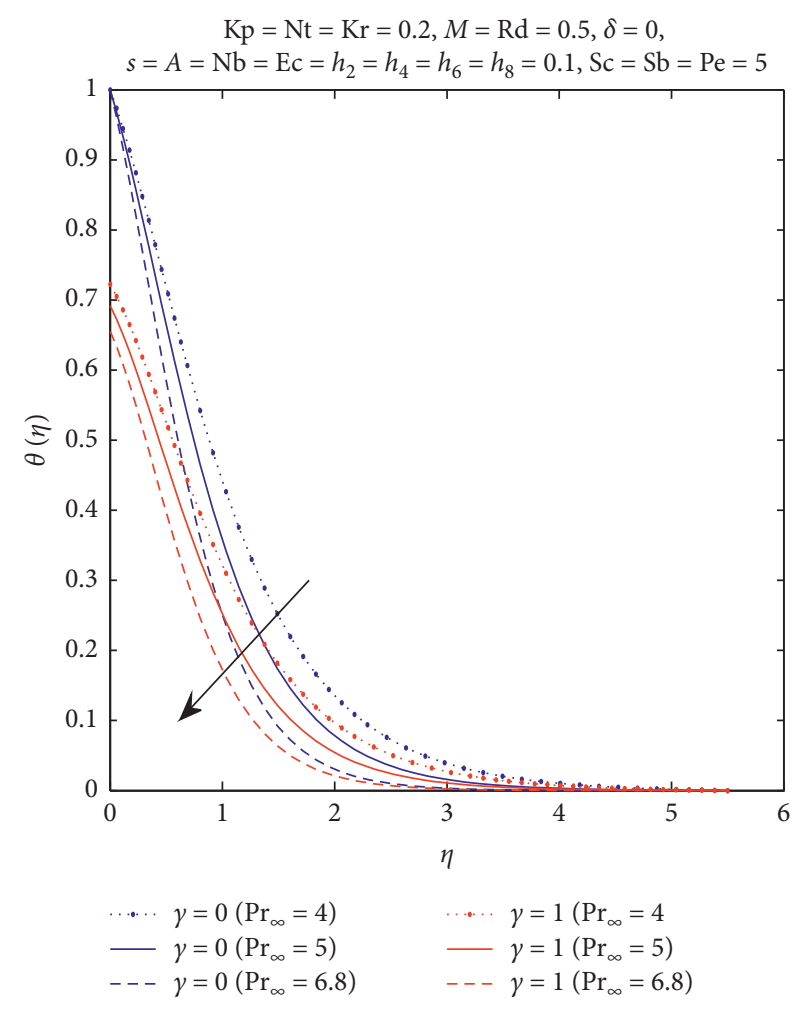

Figure 3: Temperature profile $\theta(\eta)$ for different $\operatorname{Pr}_{\infty}$.

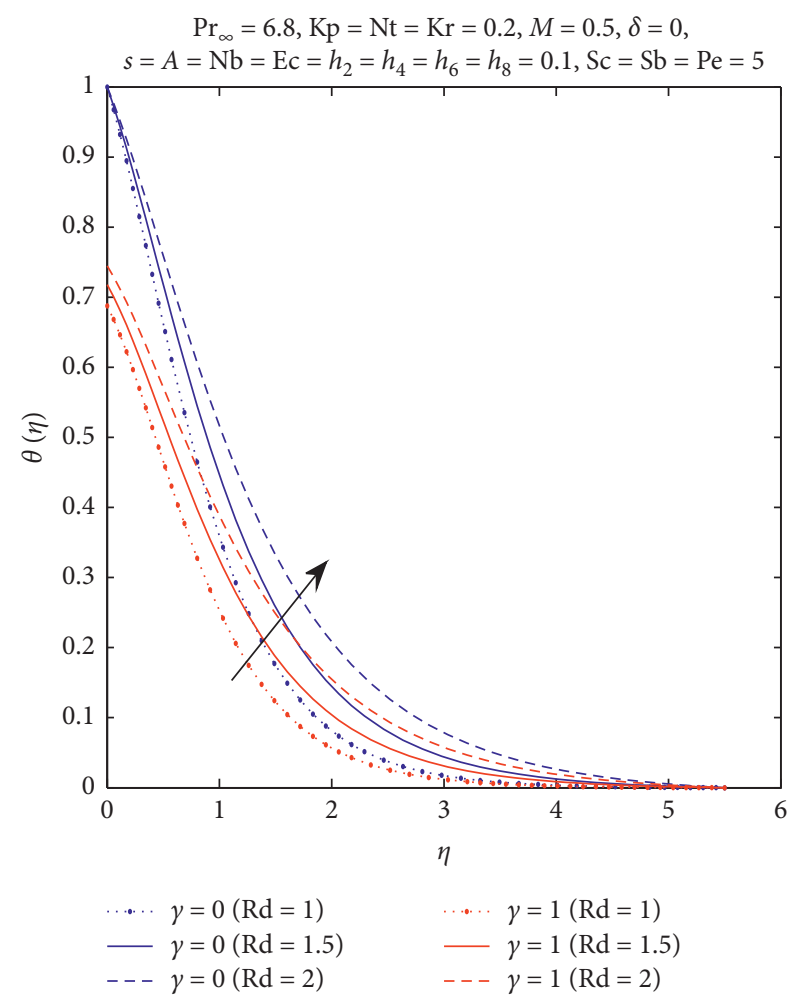

FIgURE 4: Temperature profile $\theta(\eta)$ for different Rd. 


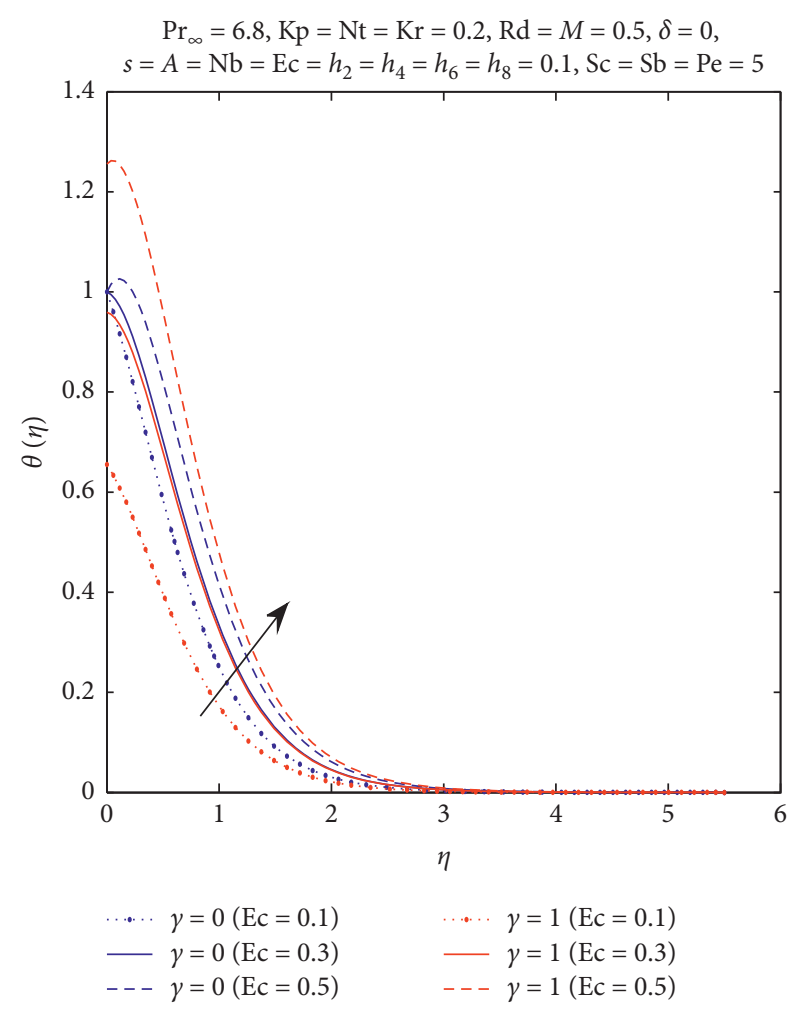

Figure 5: Temperature profile $\theta(\eta)$ for different Ec.

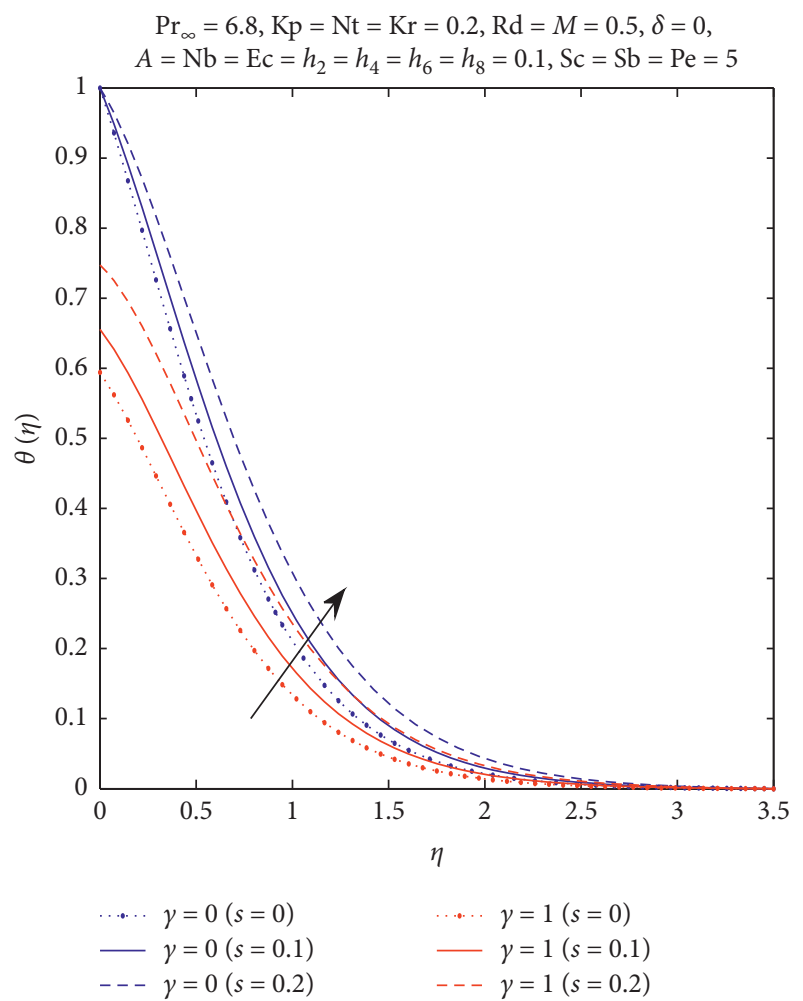

Figure 6: Temperature profile $\theta(\eta)$ for different $s$.

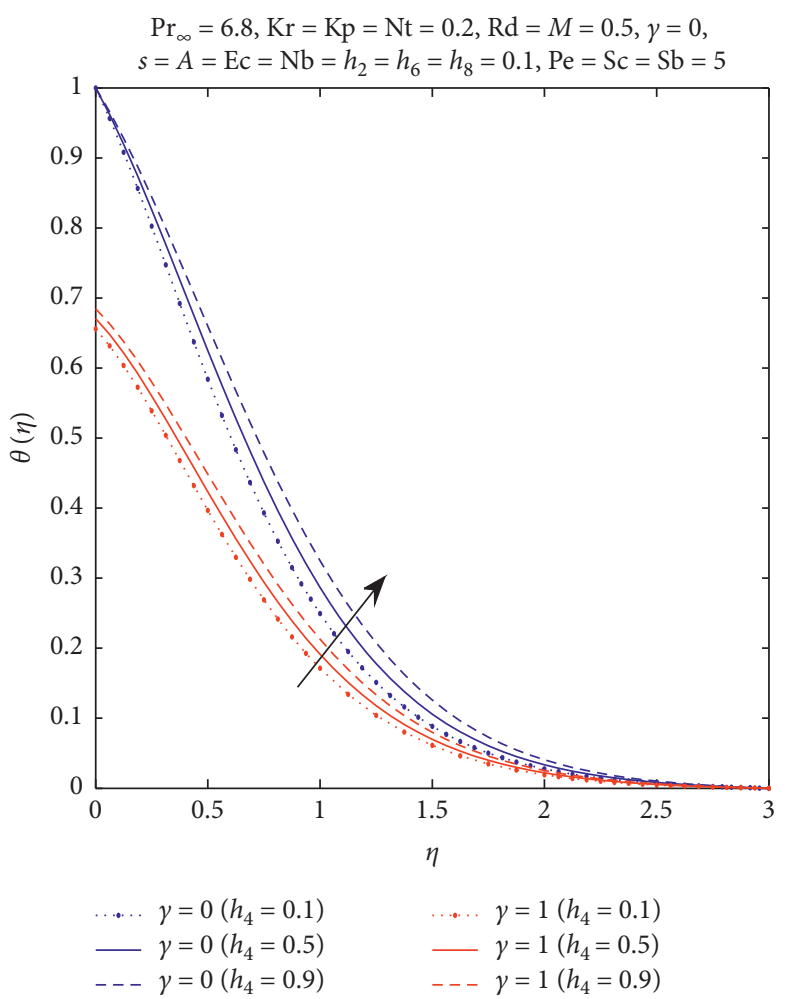

Figure 7: Temperature profile $\theta(\eta)$ for different $h_{4}$.

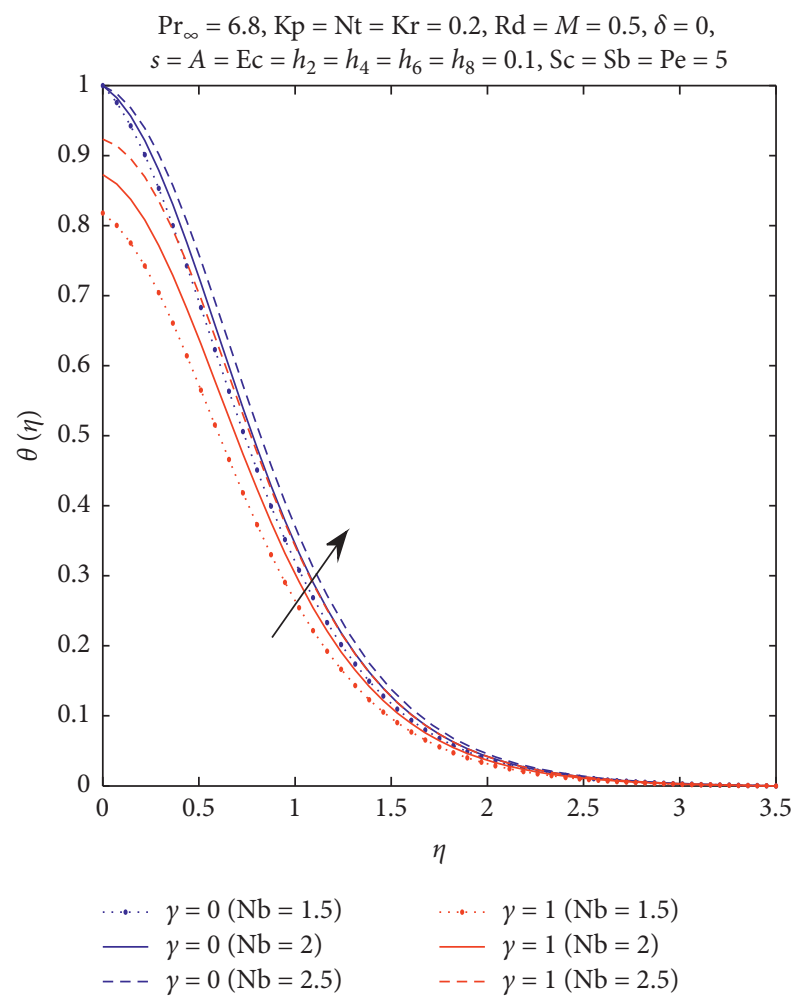

Figure 8: Temperature profile $\theta(\eta)$ for different $\mathrm{Nb}$. 


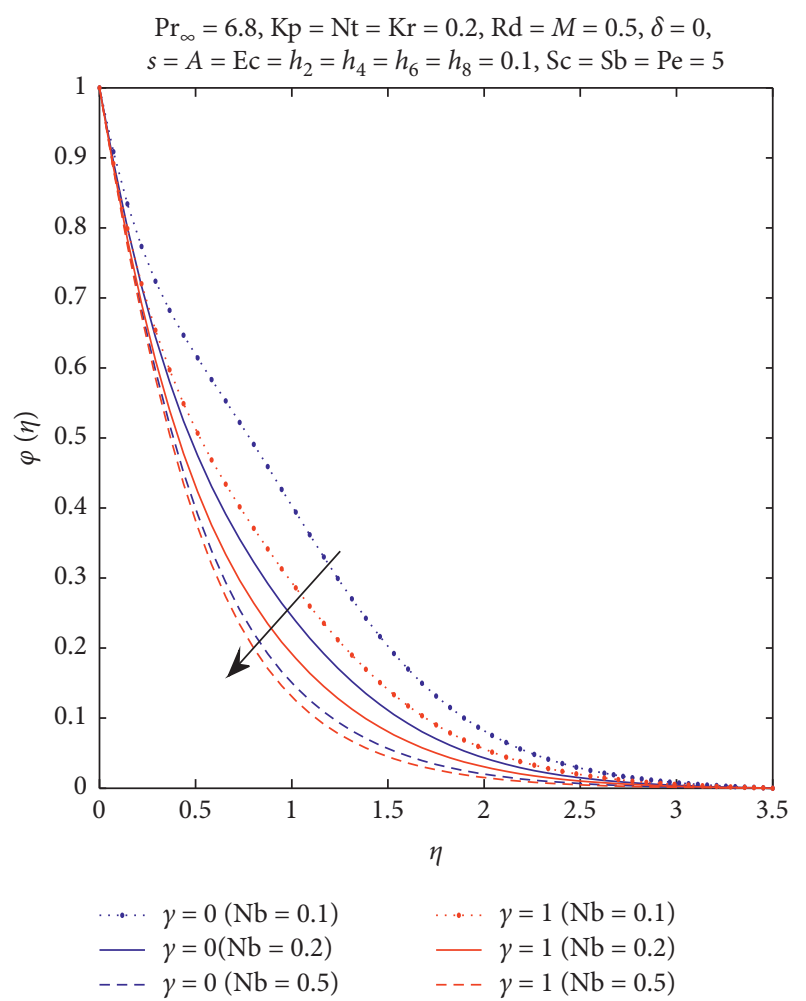

Figure 9: Concentration profile $\phi(\eta)$ for different $\mathrm{Nb}$.

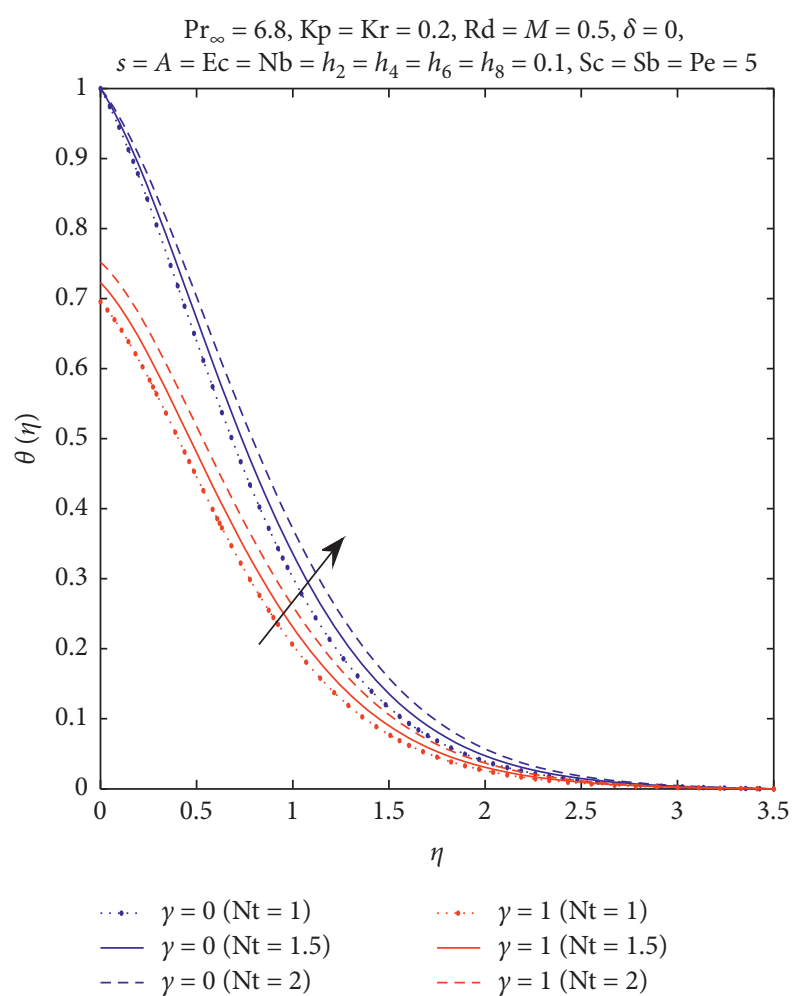

FIgUre 10: Temperature profile $\phi(\eta)$ for different Nt.

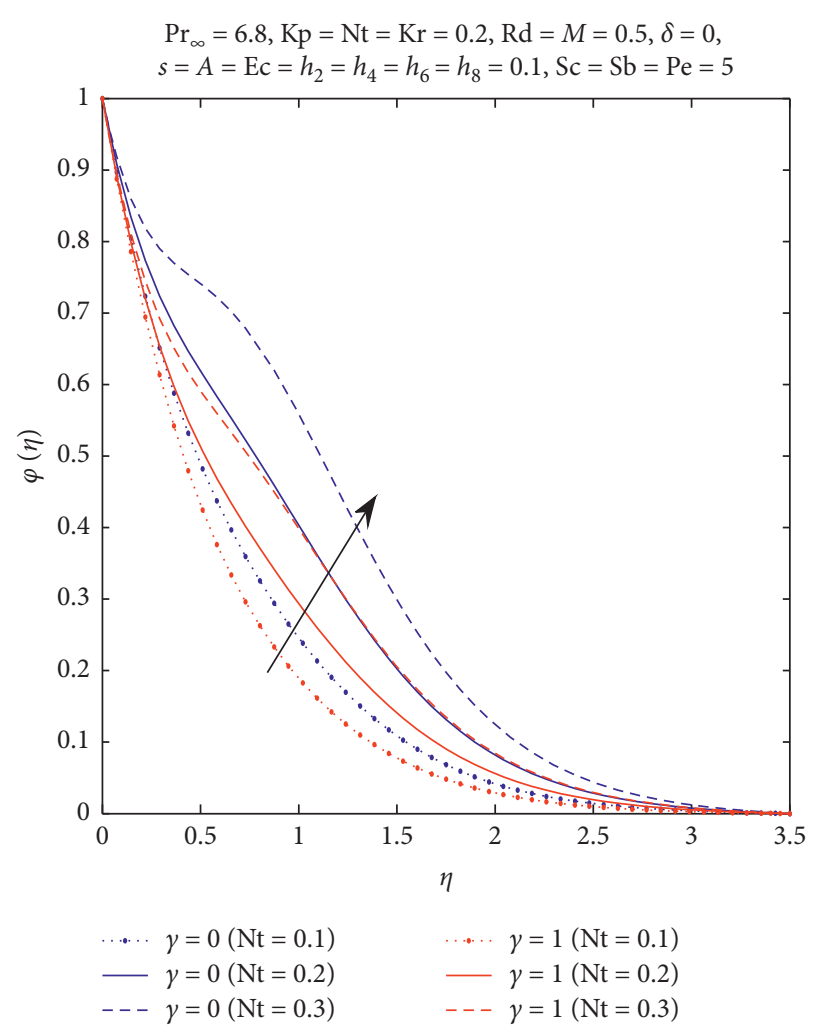

Figure 11: Concentration profile $\phi(\eta)$ for different Nt.

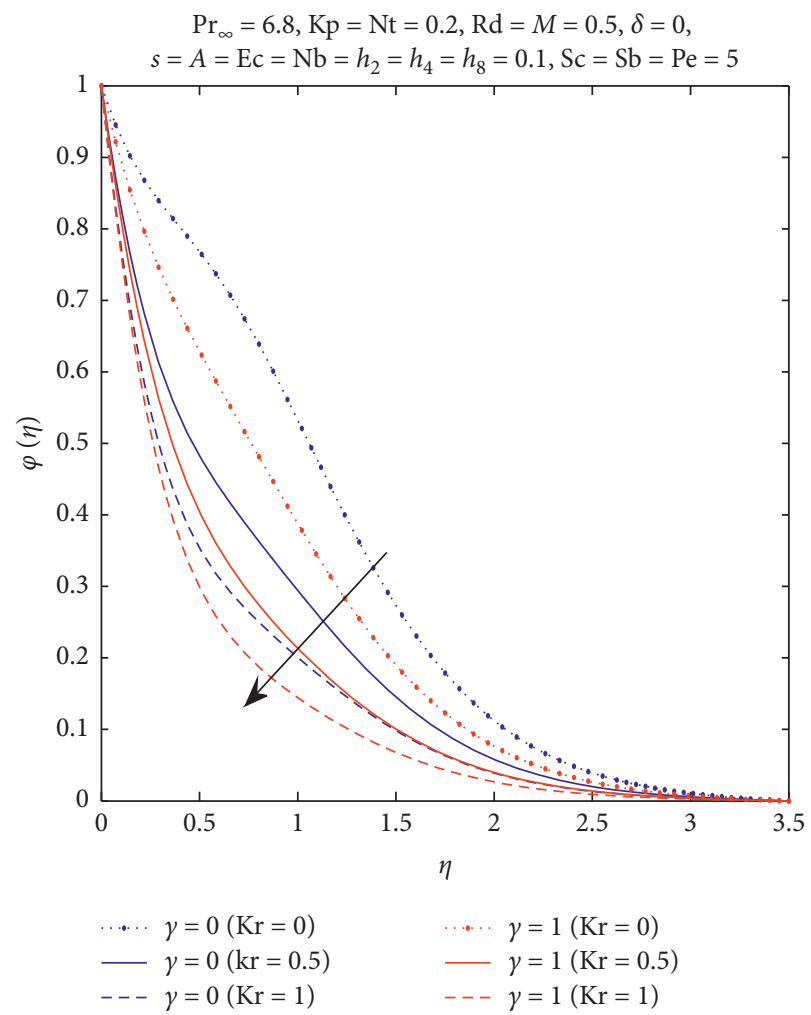

Figure 12: Concentration profile $\phi(\eta)$ for different $\mathrm{Kr}$. 


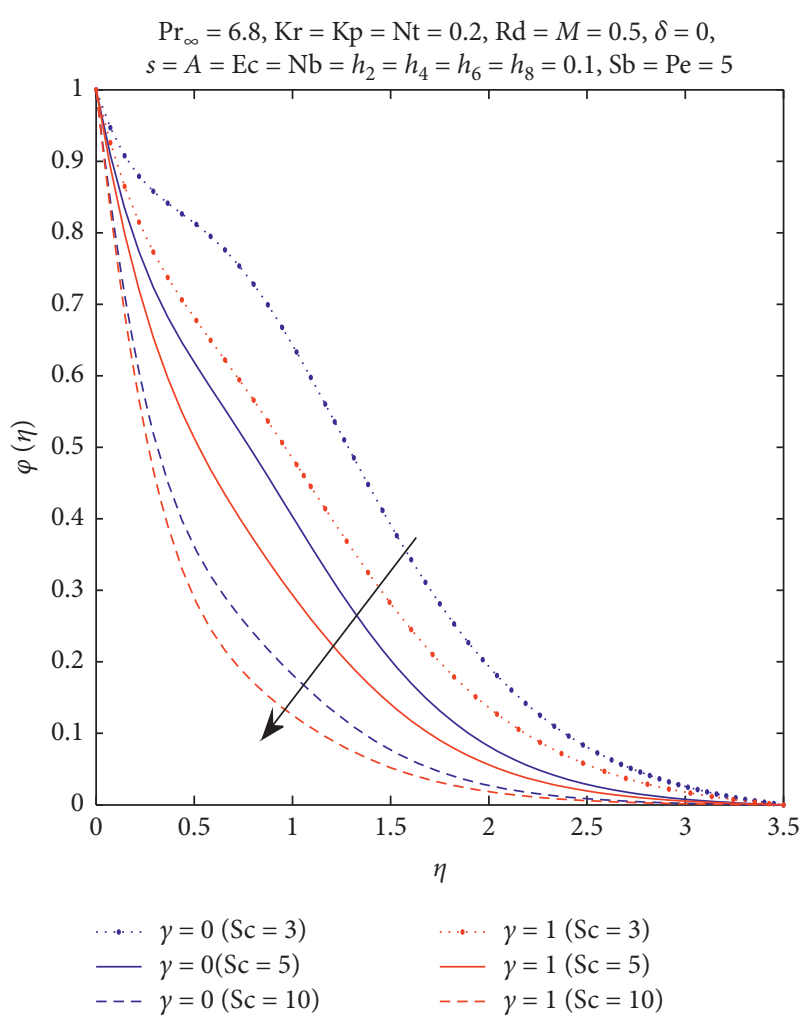

FIgURE 13: Concentration profile $\phi(\eta)$ for different Sc.

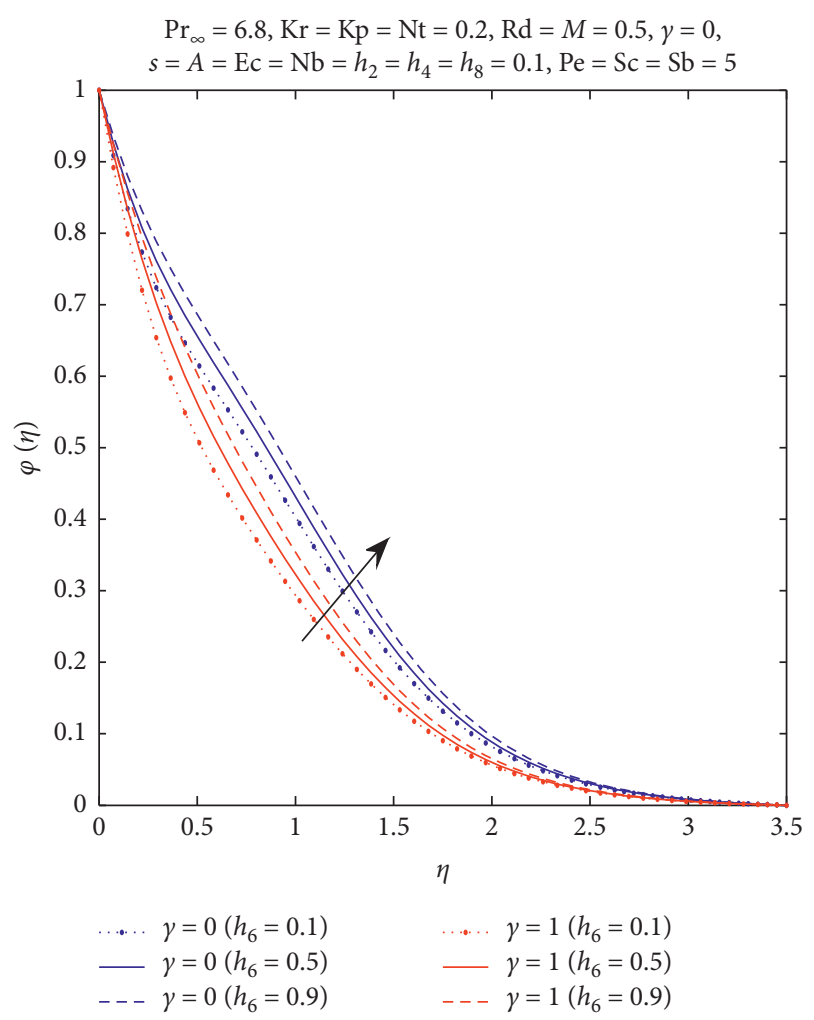

Figure 14: Concentration profile $\phi(\eta)$ for different $h_{6}$.

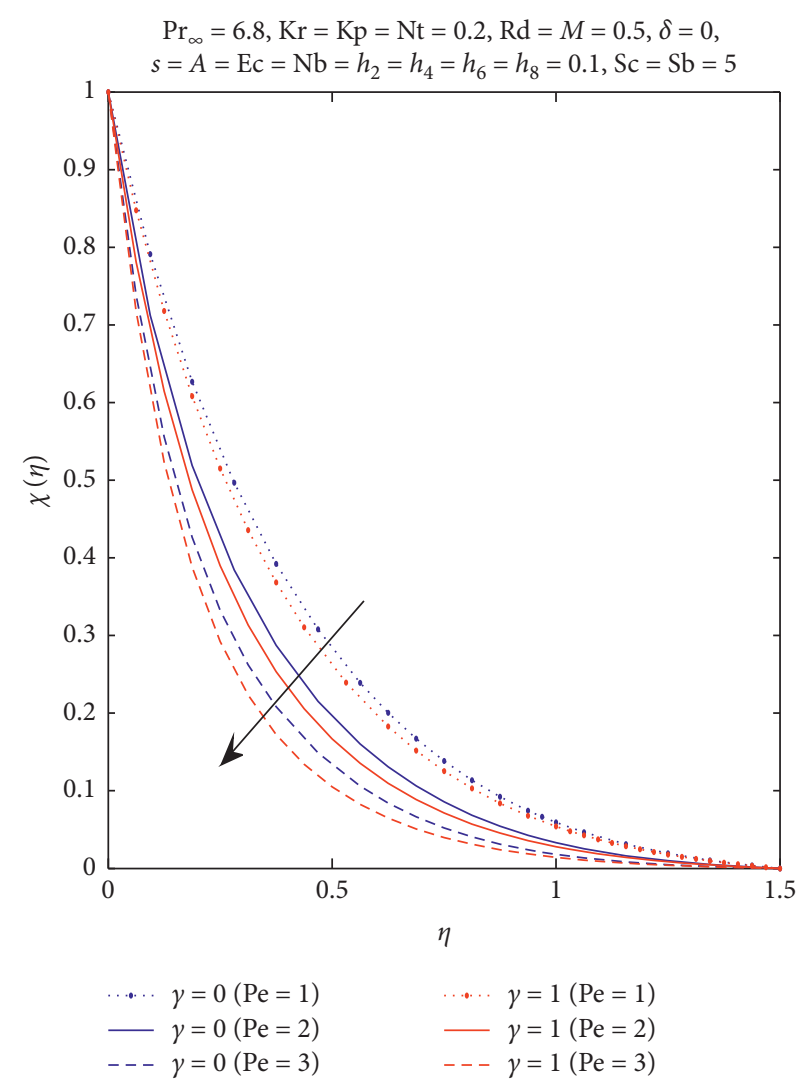

FIgURe 15: Microorganisms' profile $\phi(\eta)$ for different Pe.

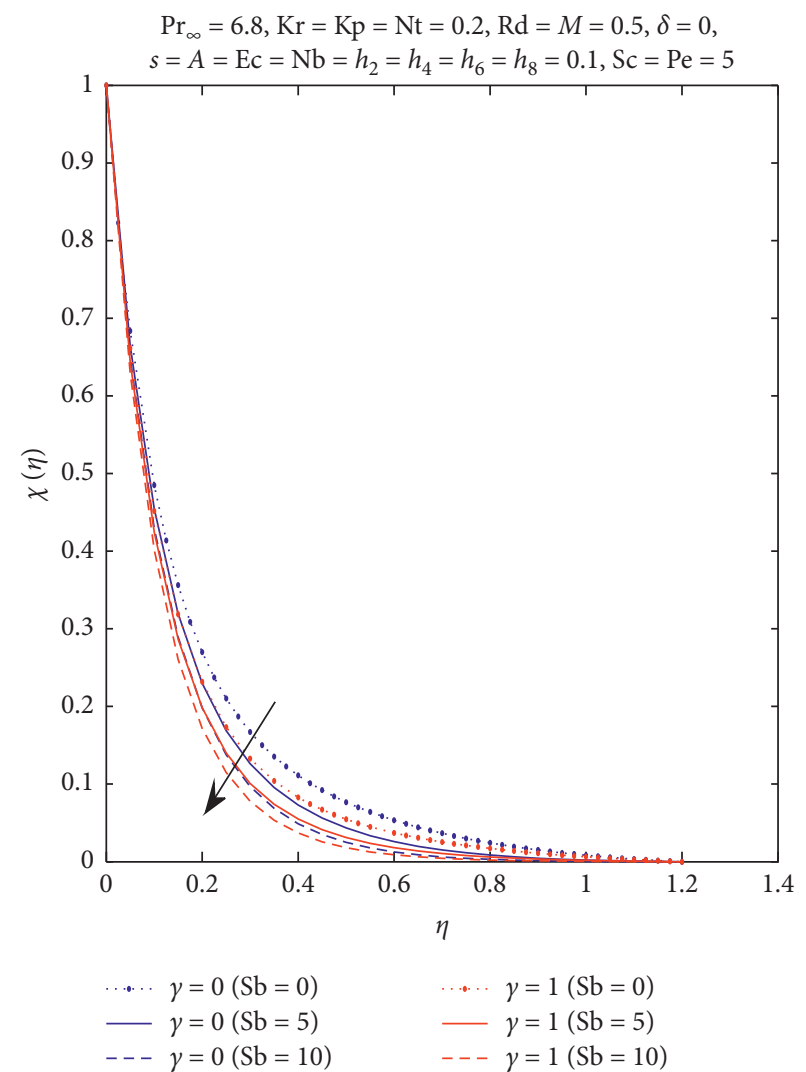

Figure 16: Microorganisms' profile $\phi(\eta)$ for different Sb. 


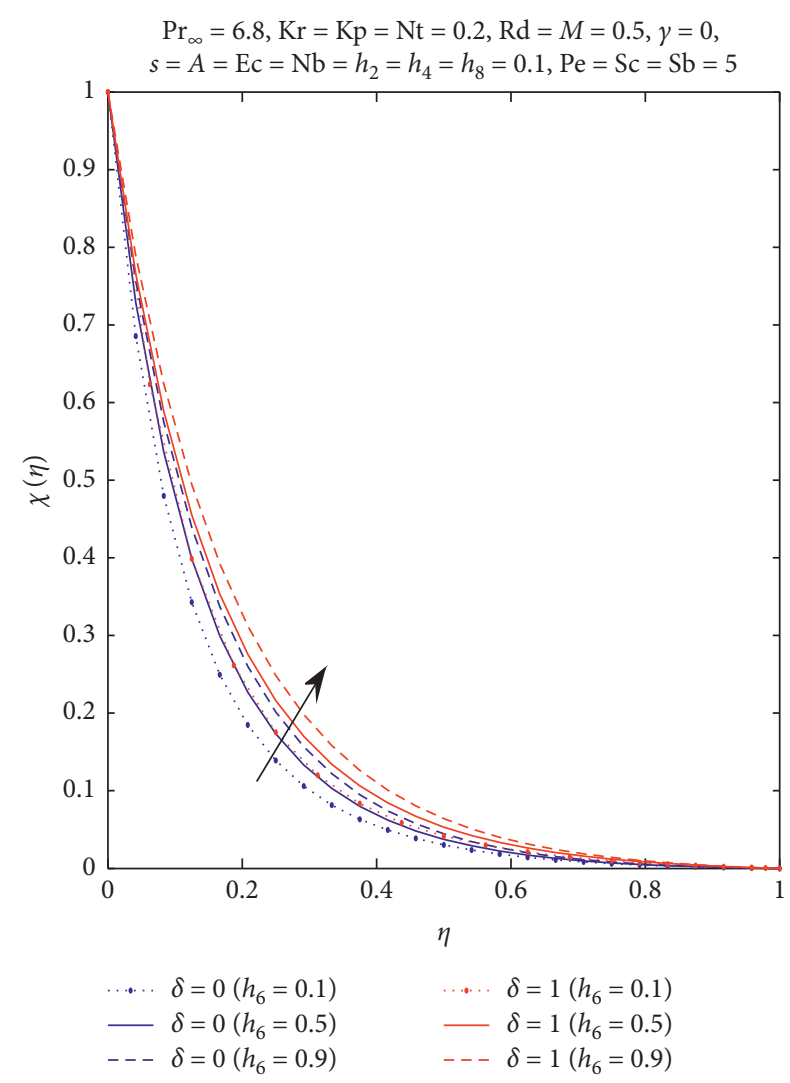

FIgURE 17: Microorganisms' profile $\phi(\eta)$ for different $h_{6}$.

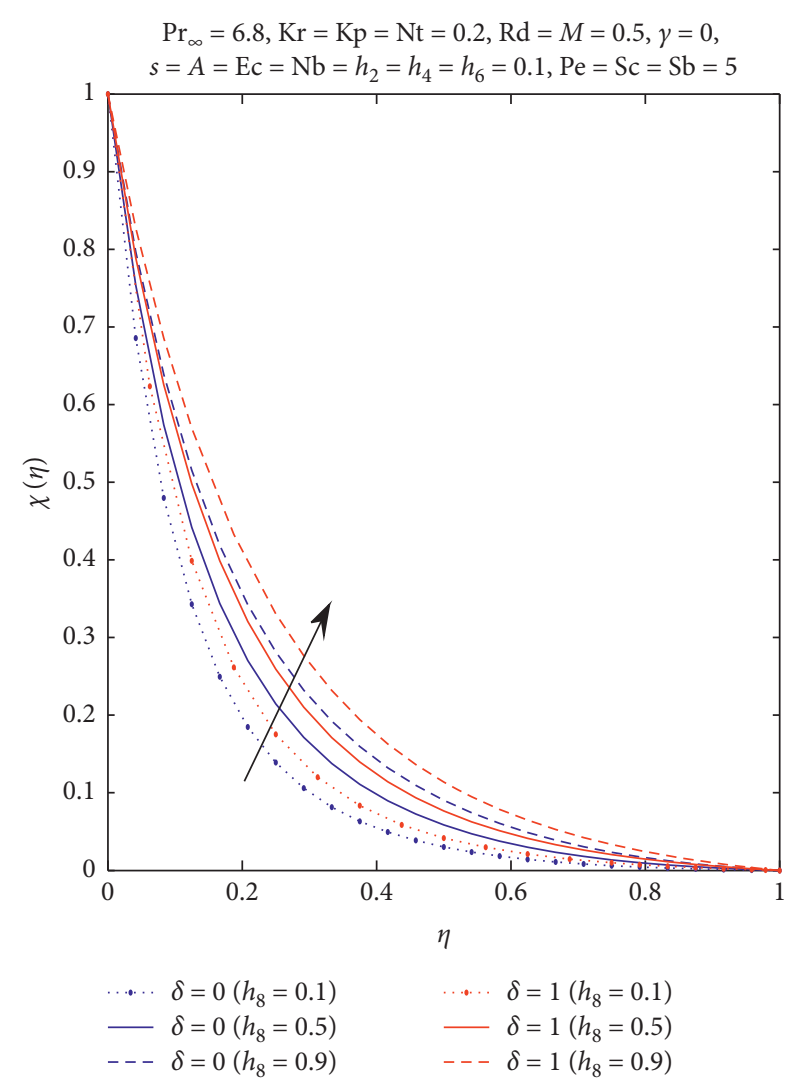

Figure 18: Microorganisms' profile $\phi(\eta)$ for different $h_{8}$.

\section{Conclusion}

The focus of the paper involves unsteady MHD flow of bionanofluid in a permeable medium taking thermal radiation and chemical reaction into account over a stretching sheet with variable thermophysical properties. The notable findings of the problem are outlined in the following [51]:

(i) The incremental values of Brownian motion parameter $\mathrm{Nb}$, thermophoresis parameter $\mathrm{Nt}$, thermal radiation parameter Rd, Eckert number Ec, and heat source parameter $s$ magnify the thermal boundary layer thickness, while an increase in Prandtl number $\operatorname{Pr}_{\infty}$ causes reduction in the thermal boundary layer thickness.

(ii) The concentration boundary layer thickness rises for thermophoresis parameter Nt and mass diffusivity parameter $h_{6}$, whereas it declines for higher values of the Brownian motion parameter $\mathrm{Nb}$, Schmidt number Sc, and chemical reaction parameter $\mathrm{Kr}$.

(iii) The increment in bioconvection Schmidt number $\mathrm{Sb}$ and Peclet number Pe reduces the boundary layer thickness of motile microorganisms, while the motile microorganisms' boundary layer shows inverse behavior for mass diffusivity parameter $h_{6}$ and microorganism parameter $h_{8}$.

(iv) Graphs have been drawn with and without slip conditions. Difference can be clearly seen through graphs as the boundary layer thickness of the slip condition is different when compared without the slip flow case.

\section{Notations}

$a>0: \quad$ A constant $\left(s^{-1}\right)$

$(u, v)$ : Fluid velocities along and normal to the flow $\left(\mathrm{ms}^{-1}\right)$

$(x, y)$ : Orthogonal Cartesian coordinates $(\mathrm{m})$

$A$ : Unsteadiness parameter

$A_{1}$ : Dimensionless parameter

$\beta_{o}: \quad$ Applied magnetic field $\left(\mathrm{Nm}^{-1} A^{-1}\right)$

$\mu$ : $\quad$ Dynamic viscosity (Pas)

$\rho: \quad$ Fluid's viscosity $\left(\mathrm{kgm}^{-3}\right)$

$\sigma: \quad$ Fluid's electrical conductivity $\left(\mathrm{Sm}^{-1}\right)$ ( $\mathrm{S}$ is siemens)

M: $\quad$ Dimensionless magnetic variable

Kp: Porosity variable

$T: \quad$ Fluid's temperature $(\mathrm{K})$

$T_{w}: \quad$ Constant wall temperature $(\mathrm{K})$

$T_{\infty}: \quad$ Free-stream temperature $(\mathrm{K})$

$k(T)$ : Variable thermal conductivity $\left(\mathrm{Wm}^{-1} \mathrm{~K}^{-1}\right)$

$\alpha: \quad$ Thermal diffusivity $\left(\mathrm{m}^{2} \mathrm{~s}^{-1}\right)$

$\delta: \quad$ Slip parameter

$C_{p}: \quad$ Heat capacity at constant pressure $\left(\mathrm{Jkg}^{-1} \mathrm{~K}^{-1}\right)$

$q_{r}: \quad$ Flux due to radiation $\left(\mathrm{Wm}^{-2}\right)$

Q: $\quad$ Internal heat generation/absorption

$C_{f}$ : $\quad$ Skin friction coefficient

$\mathrm{Nu}_{x}$ : Local Nusselt parameter

MHD: Magnetohydrodynamics

PDEs: Partial differential equations 
$s: \quad$ Heat source/sink parameter

Rd: Thermal radiation parameter

$\mathrm{Pr}_{\infty}$ : Free-stream Prandtl number

$D_{B}$ : Brownian coefficient $\left(\mathrm{m}^{2} \mathrm{~s}^{-1}\right)$

$D_{T}: \quad$ Thermophoretic coefficient $\left(\mathrm{m}^{2} \mathrm{~s}^{-1}\right)$

$D_{m}$ : Diffusivity of microorganisms $\left(\mathrm{m}^{2} \mathrm{~s}^{-1}\right)$

$D_{n}: \quad$ Diffusivity coefficient $\left(\mathrm{m}^{2} \mathrm{~s}^{-1}\right)$

$\tau_{1}$ : $\quad$ Ratio of effective heat capacitance of the nanoparticle to the base fluid

$(\rho c)_{p}$ : Nanoparticle heat capacity $\left(\mathrm{JK}^{-1} \mathrm{~m}^{3}\right)$

Nb: Brownian motion parameter

Nt: Thermophoresis parameter

C: Concentration

$C_{w}: \quad$ Concentration at the wall

$C_{\infty}: \quad$ Ambient fluid concentration

$N$ : $\quad$ Concentration of microorganisms

$N_{w}$ : Microorganisms at the wall

$N_{\infty}$ : Microorganisms far from the wall

Le: Lewis number

Sb: Bioconvection Schmidt number

$b$ : Chemotaxis constant (m)

$w_{c}$ : $\quad$ Maximum cell swimming speed $\left(\mathrm{ms}^{-1}\right)$

Pe: Peclet number

$\mathrm{Sh}_{x}$ : Local Sherwood parameter

$\mathrm{Nn}_{x}$ : Local density parameter of the motile microorganisms

ODEs: Ordinary differential equations

FDM: Finite difference method.

\section{Data Availability}

No data were used to support this study.

\section{Conflicts of Interest}

The authors declare that they have no conflicts of interest.

\section{References}

[1] S. U. Choi and J. A. Eastman, Enhancing Thermal Conductivity of Fluids with Nanoparticles (No. ANL/MSD/CP-84938; CONF-951135-29), Argonne National Lab., Chicago, IL, USA, 1995.

[2] S. Lee, S. U.-S. Choi, S. Li, and J. A. Eastman, "Measuring thermal conductivity of fluids containing oxide nanoparticles," Journal of Heat Transfer, vol. 121, no. 2, p. 280, 1999.

[3] S. Rashidi, O. Mahian, and E. M. Languri, "Applications of nanofluids in condensing and evaporating systems," Journal of Thermal Analysis and Calorimetry, vol. 131, no. 3, pp. 2027-2039, 2018.

[4] Z. Zhang, J. Cai, F. Chen, H. Li, W. Zhang, and W. Qi, "Progress in enhancement of $\mathrm{CO}_{2}$ absorption by nanofluids: a mini review of mechanisms and current status," Renewable Energy, vol. 118, pp. 527-535, 2018.

[5] C. RamReddy, P. V. S. N. Murthy, A. M. Rashad, and A. J. Chamkha, "Numerical study of thermally stratified nanofluid flow in a saturated non-Darcy porous medium," The European Physical Journal Plus, vol. 129, no. 2, p. 25, 2014.

[6] M. N. Khan, S. Nadeem, N. Ullah, and A. Saleem, "Theoretical treatment of radiative oldroyd-B nanofluid with microorganism pass an exponentially stretching sheet," Surfaces and Interfaces, vol. 21, Article ID 100686, 2020.

[7] W. A. Khan, M. Khan, and R. Malik, "Three-dimensional flow of an Oldroyd-B nanofluid towards stretching surface with heat generation/absorption," PLoS One, vol. 9, no. 8, Article ID e105107, 2014.

[8] A. Raees, H. Xu, and S.-J. Liao, "Unsteady mixed nanobioconvection flow in a horizontal channel with its upper plate expanding or contracting," International Journal of Heat and Mass Transfer, vol. 86, pp. 174-182, 2015.

[9] M. J. Uddin, W. A. Khan, S. R. Qureshi, and O. Anwar Bég, "Bioconvection nanofluid slip flow past a wavy surface with applications in nano-biofuel cells," Chinese Journal of Physics, vol. 55, no. 5, pp. 2048-2063, 2017.

[10] W. A. Khan and O. D. Makinde, "MHD nanofluid bioconvection due to gyrotactic microorganisms over a convectively heat stretching sheet," International Journal of Thermal Sciences, vol. 81, pp. 118-124, 2014.

[11] M. J. Uddin, M. N. Kabir, and O. A. Bég, "Computational investigation of Stefan blowing and multiple-slip effects on buoyancy-driven bioconvection nanofluid flow with microorganisms," International Journal of Heat and Mass Transfer, vol. 95, pp. 116-130, 2016.

[12] Z. Mehmood and Z. Iqbal, "Interaction of induced magnetic field and stagnation point flow on bioconvection nanofluid submerged in gyrotactic microorganisms," Journal of Molecular Liquids, vol. 224, pp. 1083-1091, 2016.

[13] S. Siddiqa, M. Sulaiman, M. A. Hossain, S. Islam, and R. S. R. Gorla, "Gyrotactic bioconvection flow of a nanofluid past a vertical wavy surface," International Journal of Thermal Sciences, vol. 108, pp. 244-250, 2016.

[14] Z. Iqbal, Z. Mehmood, and E. N. Maraj, "Oblique transport of gyrotactic microorganisms and bioconvection nanoparticles with convective mass flux," Physica E: Low-Dimensional Systems and Nanostructures, vol. 88, pp. 265-271, 2017.

[15] M. Waqas, T. Hayat, S. A. Shehzad, and A. Alsaedi, "Transport of magnetohydrodynamic nanomaterial in a stratified medium considering gyrotactic microorganisms," Physica B: Condensed Matter, vol. 529, pp. 33-40, 2018.

[16] M. Ramzan, J. D. Chung, and N. Ullah, "Radiative magnetohydrodynamic nanofluid flow due to gyrotactic microorganisms with chemical reaction and non-linear thermal radiation," International Journal of Mechanical Sciences, vol. 130, pp. 31-40, 2017.

[17] K. Das, "Impact of thermal radiation on MHD slip flow over a flat plate with variable fluid properties," Heat and Mass Transfer, vol. 48, no. 5, pp. 767-778, 2012.

[18] C. RamReddy and P. Naveen, "Analysis of activation energy and thermal radiation on convective flow of a power-law fluid under convective heating and chemical reaction," Heat Transfer-Asian Research, vol. 48, no. 6, pp. 2122-2154, 2019.

[19] A. Aziz, W. A. Khan, and I. Pop, "Free convection boundary layer flow past a horizontal flat plate embedded in porous medium filled by nanofluid containing gyrotactic microorganisms," International Journal of Thermal Sciences, vol. 56, pp. $48-57,2012$.

[20] W. N. Mutuku and O. D. Makinde, "Hydromagnetic bioconvection of nanofluid over a permeable vertical plate due to gyrotactic microorganisms," Computers \& Fluids, vol. 95, pp. 88-97, 2014.

[21] M. T. Sk, K. Das, and P. K. Kundu, "Multiple slip effects on bioconvection of nanofluid flow containing gyrotactic microorganisms and nanoparticles," Journal of Molecular Liquids, vol. 220, pp. 518-526, 2016. 
[22] T. Anwar, P. Kumam, D. Baleanu, I. Khan, and P. Thounthong, "Radiative heat transfer enhancement in MHD porous channel flow of an Oldroyd-B fluid under generalized boundary conditions," Physica Scripta, vol. 95, no. 11, Article ID 115211, 2020.

[23] O. D. Makinde and I. L. Animasaun, "Bioconvection in MHD nanofluid flow with nonlinear thermal radiation and quartic autocatalysis chemical reaction past an upper surface of a paraboloid of revolution," International Journal of Thermal Sciences, vol. 109, pp. 159-171, 2016.

[24] N. Begum, S. Siddiqa, and M. A. Hossain, "Nanofluid bioconvection with variable thermophysical properties," Journal of Molecular Liquids, vol. 231, pp. 325-332, 2017.

[25] F. T. Tuz Zohra, M. Jashim Uddin, A. I. Md. Ismail, and O. Anwar Bég, "Bioconvective electromagnetic nanofluid transport from a wedge geometry:Simulation of smart electroconductive bio-nanopolymer processing," Heat TransferAsian Research, vol. 47, no. 1, pp. 231-250, 2018.

[26] J. B. Mathieu and S. Martel, "Aggregation of magnetic microparticles in the context of targeted therapies actuated by a magnetic resonance imaging system," Journal of Applied Physics, vol. 106, no. 4, Article ID 044904, 2009.

[27] A. Ali, S. Saleem, S. Mumraiz, A. Saleem, M. Awais, and D. N. Khan Marwat, "Investigation on $\mathrm{TiO}_{2}-\mathrm{Cu} / \mathrm{H}_{2} \mathrm{O}$ hybrid nanofluid with slip conditions in MHD peristaltic flow of Jeffrey material," Journal of Thermal Analysis and Calorimetry, vol. 143, no. 3, pp. 1985-1996, 2021.

[28] Z. M. Mburu, S. Mondal, and P. Sibanda, "Numerical study on combined thermal radiation and magnetic field effects on entropy generation in unsteady fluid flow past an inclined cylinder," Journal of Computational Design and Engineering, vol. 8, no. 1, pp. 149-169, 2020.

[29] F. Mabood, T. Muhammad, M. K. Nayak, H. Waqas, and O. D. Makinde, "EMHD flow of non-Newtonian nanofluids over thin needle with Robinson's condition and Arrhenius pre-exponential factor law," Physica Scripta, vol. 95, no. 11, Article ID 115219, 2020.

[30] E. O. Fatunmbi and A. Adeniyan, "Nonlinear thermal radiation and entropy generation on steady flow of magnetomicropolar fluid passing a stretchable sheet with variable properties," Results in Engineering, vol. 6, Article ID 100142, 2020.

[31] B. S. Dandapat, B. Santra, and K. Vajravelu, "The effects of variable fluid properties and thermo-capillarity on the flow of a thin film on an unsteady stretching sheet," International Journal of Heat and Mass Transfer, vol. 50, no. 5-6, pp. 991996, 2007.

[32] K. Vajravelu, K. V. Prasad, and C.-O. Ng, "Unsteady convective boundary layer flow of a viscous fluid at a vertical surface with variable fluid properties," Nonlinear Analysis: Real World Applications, vol. 14, no. 1, pp. 455-464, 2013.

[33] A. Shahsavar, A. Godini, P. T. Sardari, D. Toghraie, and H. Salehipour, "Impact of variable fluid properties on forced convection of $\mathrm{Fe}_{3} \mathrm{O}_{4} / \mathrm{CNT} /$ water hybrid nanofluid in a double-pipe mini-channel heat exchanger," Journal of Thermal Analysis and Calorimetry, vol. 137, no. 3, pp. 1031-1043, 2019.

[34] K. Naganthran, M. Mustafa, A. Mushtaq, and R. Nazar, "Dual solutions for fluid flow over a stretching/shrinking rotating disk subject to variable fluid properties," Physica A: Statistical Mechanics and Its Applications, vol. 556, Article ID 124773, 2020.

[35] T. Salahuddin, M. Arshad, N. Siddique, and I. Tlili, "Change in internal energy of viscoelastic fluid flow between two rotating parallel plates having variable fluid properties," Indian Journal of Physics, pp. 1-11, 2020.

[36] A. Shafiq, G. Rasool, C. M. Khalique, and S. Aslam, "Second grade bioconvective nanofluid flow with buoyancy effect and chemical reaction," Symmetry, vol. 12, no. 4, p. 621, 2020.

[37] G. Rasool and A. Shafiq, "Numerical exploration of the features of thermally enhanced chemically reactive radiative Powell-Eyring nanofluid flow via Darcy medium over nonlinearly stretching surface affected by a transverse magnetic field and convective boundary conditions," Applied Nanoscience, pp. 1-18, 2020.

[38] A. Shafiq, T. N. Sindhu, and C. M. Khalique, "Numerical investigation and sensitivity analysis on bioconvective tangent hyperbolic nanofluid flow towards stretching surface by response surface methodology," Alexandria Engineering Journal, vol. 59, no. 6, pp. 4533-4548, 2020.

[39] M. A. El-Hakiem and A. M. Rashad, "Effect of radiation on non-Darcy free convection from a vertical cylinder embedded in a fluid-saturated porous medium with a temperaturedependent viscosity," Journal of Porous Media, vol. 10, no. 2, 2007.

[40] S. M. M. El-Kabeir, A. J. Chamkha, and A. M. Rashad, "Effect of thermal radiation on non-Darcy natural convection from a vertical cylinder embedded in a nanofluid porous media," Journal of Porous Media, vol. 17, no. 3, 2014.

[41] A. M. Rashad and H. A. Nabwey, "Gyrotactic mixed bioconvection flow of a nanofluid past a circular cylinder with convective boundary condition," Journal of the Taiwan Institute of Chemical Engineers, vol. 99, pp. 9-17, 2019.

[42] W. A. Khan, A. M. Rashad, M. M. M. Abdou, and I. Tlili, "Natural bioconvection flow of a nanofluid containing gyrotactic microorganisms about a truncated cone," European Journal of Mechanics-B/Fluids, vol. 75, pp. 133-142, 2019.

[43] H. Babar, M. Sajid, and H. Ali, "Viscosity of hybrid nanofluids: a critical review," Thermal Science, vol. 23, no. 3, pp. 1713-1754, 2019.

[44] M. U. Sajid and H. M. Ali, "Thermal conductivity of hybrid nanofluids: a critical review," International Journal of Heat and Mass Transfer, vol. 126, pp. 211-234, 2018.

[45] A. Wahab, A. Hassan, M. A. Qasim, H. M. Ali, H. Babar, and M. U. Sajid, "Solar energy systems-potential of nanofluids," Journal of Molecular Liquids, vol. 289, Article ID 111049, 2019.

[46] M. U. Sajid and Y. Bicer, "Nanofluids as solar spectrum splitters: a critical review," Solar Energy, vol. 207, pp. 9741001, 2020.

[47] M. U. Sajid, H. M. Ali, A. Sufyan, D. Rashid, S. U. Zahid, and W. U. Rehman, "Experimental investigation of $\mathrm{TiO}_{2}$-water nanofluid flow and heat transfer inside wavy mini-channel heat sinks," Journal of Thermal Analysis and Calorimetry, vol. 137, no. 4, pp. 1279-1294, 2019.

[48] N. A. Amirsom, M. J. Uddin, M. F. Md Basir, A. Kadir, O. A. Bég, and A. I. Md. Ismail, "Computation of melting dissipative magnetohydrodynamic nanofluid bioconvection with second-order slip and variable thermophysical properties," Applied Sciences, vol. 9, no. 12, p. 2493, 2019.

[49] J. Kierzenka and L. F. Shampine, "A BVP solver based on residual control and the Maltab PSE," ACM Transactions on Mathematical Software, vol. 27, no. 3, pp. 299-316, 2001.

[50] T. Hayat, Q. Hussain, and T. Javed, "The modified decomposition method and Padé approximants for the MHD flow over a non-linear stretching sheet," Nonlinear Analysis: Real World Applications, vol. 10, no. 2, pp. 966-973, 2009. 
[51] F. Mabood and A. Mastroberardino, "Melting heat transfer on MHD convective flow of a nanofluid over a stretching sheet with viscous dissipation and second order slip," Journal of the Taiwan Institute of Chemical Engineers, vol. 57, pp. 62-68, 2015.

[52] H. I. Andersson, "Slip flow past a stretching surface," Acta Mechanica, vol. 158, no. 1-2, pp. 121-125, 2002.

[53] M. A. A. Hamad, M. J. Uddin, and A. I. M. Ismail, "Investigation of combined heat and mass transfer by lie group analysis with variable diffusivity taking into account hydrodynamic slip and thermal convective boundary conditions," International Journal of Heat and Mass Transfer, vol. 55, no. 4, pp. 1355-1362, 2012. 